Campbell University School of Law

Scholarly Repository @ Campbell University School of Law

\title{
No Need to Toss a Coin: Conflicting Scientific Expert Testimonies and Intellectual Due Process
}

Gustavo Ribeiro

Campbell University School of Law, gribeiro@campbell.edu

Follow this and additional works at: https://scholarship.law.campbell.edu/fac_sw

Part of the Evidence Commons

\section{Recommended Citation}

Gustavo Ribeiro, No Need to Toss a Coin: Conflicting Scientific Expert Testimonies and Intellectual Due Process, 12 Law Prob. Risk 299 (2013).

Available at: https://scholarship.law.campbell.edu/fac_sw/186

This Article is brought to you for free and open access by the Faculty Scholarship at Scholarly Repository @ Campbell University School of Law. It has been accepted for inclusion in Scholarly Works by an authorized administrator of Scholarly Repository @ Campbell University School of Law. 


\title{
No need to toss a coin: conflicting scientific expert testimonies and intellectual due process
}

\author{
Gustavo Sampaio A. Ribeiro ${ }^{\dagger}$ \\ Doctoral Student, Harvard Law School
}

[Received on 18 February 2013; revised on 27 May 2013; accepted on 29 May 2013]

\begin{abstract}
This article focuses on the question of how decision makers with no relevant scientific background can (if at all) legitimately evaluate conflicting scientific expert testimonies and determine their relative reliability. Sceptics argue that non-experts can never reach justifiable conclusions regarding the merits of conflicting expert testimonies because they lack the fundamental epistemic capacity to make such judgement calls. In this article, I draw on works on epistemology, philosophy of practical reasoning, philosophy of science, science and technology studies, and legal theory in order to scrutinize recent proposals to solve the problem of conflicting scientific expert testimonies. Addressing this question is of ultimate importance due to the idea that immanent in the idea of rule-of-law there is an intellectual due process norm, which articulates that epistemically arbitrary legal decisions are also not legally justified. This article is divided into two Sections. In Section 2, I describe the basic philosophical inquiries underlying the debate about expert testimony. In particular, I first elaborate on the philosophy of testimony and its epistemic justifications, then move to the idea of epistemic deference, and finish with philosophical accounts of expertise. Section 3 presents the problem of conflicting scientific expert testimonies and analyses recent attempts to solve it as formulated by Ward Jones, Alvin Goldman and Scott Brewer. I argue that there is no single criterion (or set of criteria) upon which the non-expert could rely in order to make a rationally justified decision in each and every case in which he faces conflicting scientific expert testimonies. The alternative view here defended is to stop looking for an epistemic panacea and accept the idea that testimonial reliability operates differently within different kinds of testimony - and differently within the same kind of testimony at different times.
\end{abstract}

Keywords: expert evidence; legal reasoning; epistemology.

\section{Introduction}

This article focuses on those situations in which non-expert legal decision makers must weigh conflicting scientific expert testimonies. Specifically, I analyse the question of how decision-makers with no relevant scientific background can (if at all) legitimately evaluate conflicting scientific expert testimonies and determine their relative reliability.

Regardless of the method a legal decision-maker might rely upon to make such determinations, he must identify some plausible, explanatory judgement about the relation between the chosen criteria and a putative higher level of confidence in one expert. As Scott Brewer put it, these problems 'must be resolved in a way that is sufficiently epistemically warranted for practical (legal) purpose'. 1

\footnotetext{
${ }^{\dagger}$ Email: guribeiro@sjd.law.harvard.edu

${ }^{1}$ Scott Brewer, Scientific Expert Testimony and Intellectual Due Process, 107 YALE LAW JOURNAL pp. 1538-1681, 1998, p. 1657.
} 
Sceptics argue that non-experts can never reach justifiable conclusions regarding the merits of conflicting expert testimonies because they lack the fundamental epistemic capacity to make such judgement calls. In this article, I analyse recent attempts to reconcile this philosophical problem.

This problem is of practical importance. Putative experts are ubiquitous in contemporary, industrial society for their epistemological guidance in an ever-increasing number of sophisticated, scientifically complex, and often obscure arenas. Moreover, the adversarial nature of the USAs legal system has naturally encouraged the proliferation of professional expert witnesses. This question is also of theoretical interest because the appropriate epistemic considerations underlying it are anything but clear. Does this problem inevitably lead to insurmountable scepticism?

Finding answers to these questions will have a considerable bearing on the issue of legitimacy of decisions. For if it is the case that the judgements about the empirical facts are not epistemologically justified, then decisions have no legitimate legal justifications. This idea is enhanced by the recognition that, immanent in the idea of rule-of-law - as constructed by contemporary Western legal systemsthere is an 'intellectual due process norm'. This concept is founded on the idea that epistemically arbitrary legal decisions are also not legally justified. In other words, legal decision-makers cannot simply 'toss a coin'.

This article is divided into two Sections. In Section 2, I describe the basic philosophical inquiries underlying the debate about expert testimony. The goal is to set a common background from which to engage in the analysis of the arguments to follow.

First, I elaborate on the philosophy of testimony, and its epistemic justifications. In particular, I address questions such as: is testimony a reliable generative source of knowledge, or it is merely a transmissive epistemic instrument? I introduce reductionist and non-reductionist positions on the topic of epistemic deference to later argue that we should not assume that all knowledge acquired through testimonies shares the same characteristics. At the minimum, there are special kinds of testimonies that pose a special problem to a non-expert blind reliance be always justifiable. Given its importance, it is surprising that, until very recently, the epistemology of testimony has not received as much attention as one would imagine in philosophical literature.

Secondly, I move to the topic of epistemic deference. Here, the interesting question is: when are we justified in accepting the testimony of a speaker? After laying out the discussion, I claim that admitting testimony as evidence of one's beliefs allows us to conclude that epistemic interdependence among experts need not undermine the reliability of their beliefs and claims.

Thirdly, I explore the idea of expertise. I am mainly interested in questions such as: what does it mean to be an expert? and what features differentiate an expert from a non-expert? I scrutinize how Scott Brewer develops the topic by relying on ideas from Larry Laudan and show how Brewer's account is similar in many relevant aspects to Alvin Goldman's analysis.

Section 3 presents and analyses recent attempts to solve the problem of conflicting scientific expert testimonies ('novice/2-expert problem'). Firstly, I examine Ward Jones's 'pro-loyalist' position, which states that non-experts should resolve expert disputes by deferring to the 'dominant position' within the experts' community. I argue that his argument, as structured, is problematic, in particular because it relies on an outdated picture of science and scientific practice, which contemporary works on science and technology studies and history of science have challenged.

Secondly, I explore Alvin Goldman and Scott Brewer's approaches. Both provide more careful analyses of the problem, identifying and arguing for or against possible criteria non-experts might utilize in weighing conflicting expert testimony. I scrutinize the strengths and weaknesses of each proposal. 
Goldman offers five proposals of indirect indicators regarding expert reliability upon which the nonexpert could rely in making a legitimate decision when faced with the novice/2-expert problem. Briefly, his proposals include that non-experts assess the: (i) arguments presented by the contending experts to support their own views and critique their rival's views; (ii) agreement from additional putative experts on one side or the other of the subject in question; (iii) appraisals by 'meta-experts' of the experts' expertise (including credentials); (iv) evidence of the experts' interests and biases vis-à-vis the question at issue; and (v) evidence of the experts' past track records.

Section 3 also examines Brewer's approach. Brewer dismisses as either problematic or unworkable the following alternatives for the non-expert: (i) substantive second-guessing of the experts' reasoning; (ii) evaluation canons of rational evidentiary support; (iii) assessing the experts' demeanour; and (iv) assessing the experts' credentials. I evaluate whether Brewer's arguments for dismissing each alternative are sound and persuasive. Finally, I analyse Brewer's 'two-hat' solution, which argues for decision-makers who possess both legal legitimacy and epistemic competence with the basic formal tools of scientific analysis.

My general claim is that Brewer's particular articulation of the problem necessarily lends itself to his offered scepticism (and self-declared state of aporia). However, I believe that with the issue structured differently, such scepticism is not inevitable.

In this sense, I argue that, despite Brewer's scepticism, there are reasons to believe that non-expert legal decision-makers facing conflicting scientific expert testimonies can make legitimate epistemically justified decisions regarding the experts' reliability. The solution is to recognize that there is no single criterion (or set of criteria) upon which the non-expert can rely in order to make rationally justified decisions in each and every case in which he faces conflicting scientific expert testimonies. Criterion that turns out to be well suited in case A may not apply in case B. In some cases, one criterion or the other might fail. But in other situations, it might not. The alternative view here defended is that the idea of testimonial reliability operates differently within different kinds of testimony-and differently within the same kind of testimony at different times. In short, what should count as a 'good' justificatory criterion varies according to context.

My article draws on works on epistemology, philosophy of practical reasoning, philosophy of science, science and technology studies and legal theory. With these tools, I expect to expose recent attempts to solve the novice/2-expert problem to philosophical scrutiny, in the hope of putting them on a more reliable epistemological foundation, while bringing the whole discussion closer to law and legal settings. I should say, however, that this inquiry is structured more as an exploratory investigation; my main concern is at identifying problems and examining proposed solutions, not operationalizing in detail any definitive solutions.

\section{Scientific expert testimony: basic inquiries}

\subsection{Factual inferences in legal reasoning}

We shall start from the beginning. Most times when deciding cases, legal decision-makers have to make inferences about factual claims. ${ }^{2}$ They have to bring to light several empirical

\footnotetext{
${ }^{2}$ The importance of fact-finding to the outcome of legal decisions was already long ago stressed in American legal scholarship, perhaps most famously by legal realist Jerome Frank: 'No matter how certain the legal rules may be, the decisions remain at the mercy of the courts' fact-finding. If there is doubt about what a court, in a lawsuit, will find were the facts, then there is at least equal doubt its decisions.' (JEROME FRANK, COURTS ON TRIAL, 1949, p. 15).
} 


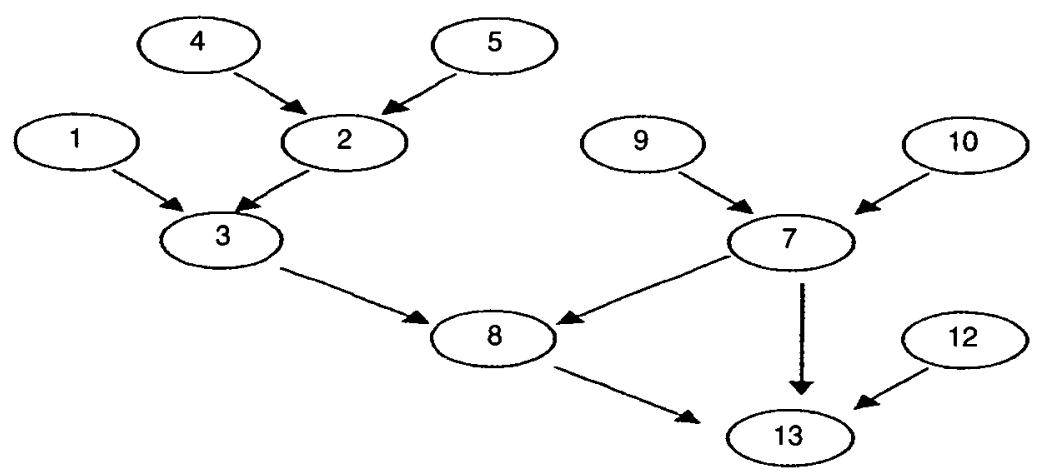

FIG. 1. (Douglas Walton, Argumentation and Theory of Evidence, 2 New trends in criminal investigation and practice, pp. 711-732, 2000, p. 723).

and theoretical arguments in order to provide support for the factual inferences that will form their legal premises. ${ }^{3}$

Consider the following statement: 'whoever, by means of an illicit act, inflicts harm on another, will be forced to compensate him; the illicit act X, caused by A, inflicted harm on B; therefore, A must compensate B'. This is an example of a legal argument, and its logical validity depends also upon the different justifications used to support the factual statements (in this case: 'the illicit act X, caused by $A$, inflicted harm to B'). At the same time, these factual inferences serve as a kind of justification for the legal decision. ${ }^{4}$

Another insight that underlines the importance of this research inquiry is the fact that most legal arguments do not depend upon a single factual inference. Actually, the factual inferences in legal reasoning are usually constructed through several different, yet interconnected, inferences. These inferences form a 'web', whose conclusions appear as factual premises of the reasoning of the decision-maker. ${ }^{5}$

One example of such inferential networks can be visualized in the following way:

In Fig. 1, the circles represent propositions that form inferences as premises and/or conclusions, and the arrows represent logical relations among the different propositions each arrow connects. In this representation, each inference has three propositions (two premises and one conclusion), and two arrows that connect them. For instance, propositions 4 and 5 are premises that, together, form conclusion 2. Proposition 2, in turn, together with proposition 1 forms conclusion 3.

Each step in this framework demands from the decision-maker intermediary decisions that subject him to justificatory inquiries, which he should be able to meet, as a necessary condition so that the legal decision in the case can be rendered as 'rationally justified'. Of further importance

\footnotetext{
${ }^{3}$ This insight is related to what Teubner calls the 'epistemic trap' of modem law. The idea is that law cannot immunize itself against other accounts of reality provided by different systems in society (see Gunther Teubner, How the Law Thinks: Toward a Constructivist Epistemology of Law, 23 LAW AND SOCIETY REVIEW n. 5, pp. 727-757, 1989, p. 745).

${ }^{4}$ Luis F. Schuartz, Interdisciplinaridade e Adjudicą̧āo: Caminhos e Descaminhos da Ciência no Direito, 232 REVISTA BRASILEIRA DE FILOSOFIA, 2009.

${ }^{5}$ See Ibid.
} 
is the recognition that each step taken in the network is 'defeasible' (in a broad sense, according to Walton ${ }^{6}$ ) and its defeasibility is spread through the whole network and chain of inferences.

So far, so good. But how should the factual inferences themselves be justified?

This question becomes even more important if we acknowledge that, in many situations: (1) these factual inferences involve some kind of scientific knowledge; ${ }^{7}(2)$ the vast majority of legal decisionmakers are not scientists; (3) non-scientists are many times not able to assess and make use of scientific information in arguments and decisions. These difficulties become explicit when we question how non-scientist legal decision-makers could be able to render scientific factual inferences as 'proven' during the legal decision-making process. In other words, there is a lack of explicit criteria according to which a legal decision-maker should assign a given factual scientific inference the status of "believed with sufficient justification for the purposes of the legal system, 8

These concerns are of further special relevance whenever some kind of epistemic deference is present. ${ }^{9}$ For example, when a judge defers to scientific expert testimony about a particular empirical claim in a given trial, as in issues related to forensic evidence in a criminal trial or the economic effects in antitrust litigation.

Recognition of the ubiquity of non-legal inferences in legal decision-making, together with the acknowledgement that several non-legal inferences used in legal reasoning are defeasible and that epistemic deference in legal reasoning is routine, are at the core of the following problem. ${ }^{10}$ Whenever we have competition among theories, methods and/or data concerning non-trivial factual inferences involved in legal reasoning, the legal decision-maker finds himself in the position of an unauthorized arbiter of a competition in which he will be called to declare the winner from an epistemologically problematic point of view, yielding a problematic lack of rationality and legitimacy in the decision from a 'legal' point of view. ${ }^{11}$

\subsection{Testimony as a source of justified belief}

Before entering into the discussion of scientific expert testimony in particular, I will briefly go over some concepts and theoretical insights available in the philosophy literature that might help

\footnotetext{
${ }^{6}$ Following Godden and Walton, here I make use of the expressions 'defeasible' and 'defeasibility' to incorporate not only the addition of extra premises that undermine the strength of the argument, but also hypotheses of elimination or modification of the original premises (David Godden and Douglas Walton, Defeasibility in Judicial Opinion: Logical or Procedural?, 28 INFORMAL LOGIC, pp. 6-19, 2008, p. 10). To yet different senses of defeasibility, see Giovanni Sartor, Defeasibility in Legal Reasoning, 24 RECHTSTHEORIE, pp. 281-316, 1993; Juan C. Bayón, Why is Legal Reasoning Defeasible?, in PLURALISM IN LAW, (A. Soeteman ed.), 2001; and Jaap Hage, Law and Defeasibility, 11 ARTIFICIAL INTELLIGENCE AND LAW, pp. 221-243, 2004.

${ }^{7}$ Here I am using the term 'knowledge' in a really 'broad' way, without at this stage worrying about epistemological distinctions between knowledge and justified belief, and the necessary and sufficient conditions for each.

${ }^{8}$ Brewer, supra n 1 p. 1541.

${ }^{9}$ Harry Collins and Evans call the issue of deference to expert 'the pressing intellectual problem of the age' (See, Harry Collins and Rob Evans, The Third Wave of Science Studies: Studies of Expertise and Experience, 32 SOCIAL STUDIES OF SCIENCE, n. 2, pp. 235-296, 2002).

${ }^{10}$ Schuartz, supra $n 4$.

${ }^{11}$ For a more optimistic vision see Bert Black, Francisco J. Ayala and Carol Saffran-Brinks, Science and the Law in the Wake of Daubert: A New Search for Scientific Knowledge, 75 TEXAS LAW REVIEW, pp. 715-802, 1994. Also in situations where the dynamics are following models of instruction such as "inquisitorial", the risk of deficits of rationality and legitimacy are present, perhaps even to a greater degree, see Schuartz, Ibid.
} 
with our inquiry. I start with the epistemological analysis of testimony as a general source of knowledge or justified belief $(\mathrm{KJB}) .^{12}$

Although modernists have denied its proper place in modern individualistic epistemology, ${ }^{13}$ testimony is an extremely valuable source of KJB and very important in the foundation of much that we generally regard as reasonable belief. Our dependence upon it is widespread throughout different domains of personal and professional life. ${ }^{14}$ We rely on other people's testimony when we listen to the weather forecast on the radio in the mornings; when we need to know the ingredients of foods; when we need to know the history of our civilization; and when we read book reviews. The list is endless. This reliance is by no means restricted to our everyday, mundane activities. Highly sophisticated academic and professional activities also heavily rely on other people's testimony. A great deal of work in physics (or other natural sciences), for example, is collaborative and highly dependent on a series of past investigations. In particular, once we realize that most scientific propositions are not tested in isolation, but within complex networks of claims and background assumptions, ${ }^{15}$ we begin to recognize that the entire scientific enterprise is highly committed to testimony on several different levels, from the setting of experiments, to the formulation and corroboration of hypothesis, to name a few. ${ }^{16}$

In sum, if we abstained from accepting what others tell us, our lives, both practically and intellectually, would become impracticable. Given this, it is no surprise that David Hume, one of the few early modern philosophers to discuss the topic of testimony seriously, affirmed that 'there is no species of reasoning more common, more useful, and even necessary to human life, that which is derived from the testimony of men and the reports of eye-witnesses and spectators'. ${ }^{17}$

Given its importance it is surprising (or not ${ }^{18}$ ) that, until very recently, the epistemology of testimony has not received as much attention as one would imagine in the philosophical literature.

Is testimony a reliable generative source of $\mathrm{KJB}$, or it is merely a transmissive epistemic instrument? When are we justified in accepting the testimony of a speaker? Is testimony just as basic a source

\footnotetext{
${ }^{12}$ It is necessary at this point to clarify a terminological issue. Because most the discussions developed here do not consistently distinguish between the use of terms such as 'knowledge' and 'justified belief', and since for my current objectives this distinction is of secondary importance, following Brewer, supra n 11601 , I shall use ' $\mathrm{KJB}$ ' to refer indiscriminately to both knowledge and justified belief.

${ }^{13}$ Cf. C.A.J. COADY, TESTIMONY, 1992, but see David Hume, Of Miracles, in AN INQUIRY CONCERNING HUMAN UNDERSTANDING (Charles W. Hendel ed.) (1955[1748]).

14 Ibid pp. 7-8 and JENNIFER LACKEY, LEARNING FROM WORDS: TESTIMONY AS A SOURCE OF KNOWLEDGE, 2008, introduction.

${ }^{15}$ This insight, often called 'The Duhem-Quine thesis', is that a scientific proposition can never be conclusively tested in isolation, what is tested is always an entire framework or a web of beliefs. The objective was to try to show that, in principle, any scientific theory can be held in the face of apparently contrary evidence. In that, they were aiming at logical positivists ideas about the possibility of confirmation and testing of particular propositions. See W.V. Quine, Two Dogmas of Empiricism, in W.V. QUINE, FROM A LOGICAL POINT OF VIEW: 9 LOGICO-PHILOSOPHICAL ESSAYS 20, 1961.

${ }^{16}$ Cf. STEVEN SHAPIN. A SOCIAL HISTORY OF TRUTH: CIVILITY AND SCIENCE IN SEVENTEENTH CENTURY, 1994, chapter 01.

${ }^{17}$ David Hume, Of Miracles, in AN INQUIRY CONCERNING HUMAN UNDERSTANDING (Charles W. Hendel ed.) (1955[1748]), at 119 .

${ }^{18}$ Coady, for instance, notices a coincidence, if not a relation, between a dominance of an individualist ideology in the post-Renaissance Western world and the emergence of a highly individualist theory of knowledge since Descartes, together with the rise of the mathematical theory of probability in the 17th century, could explain, in part, the neglect of most philosophers to the importance of testimony. C.A.J. Coady, supra n 13, p. 13-16.
} 
of KJB as sense perception, memory and reason, or does, testimony derive whatever reliability it has from being reducible to other familiar sources of $\mathrm{KJB}$ ? These sorts of questions are widespread throughout the literature on the epistemology of testimony. Before addressing them, we have to answer a preliminary question. What precisely 'is' testimony?

2.2.1 Philosophical nature of testimony. In this subsection, I begin exploring various substantively different views of the nature of testimony and show how each proposal raises different problems and epistemic consequences. In particular, I consider five different accounts of testimony, namely: (i) a narrow view; (ii) a broad view; (iii) a moderate view; (iv) a disjunctive view; and (v) an audienceoriented view. Let us consider each one in turn.

In his 1992 seminal book, which has sparked much of the recent interest in the topic of the epistemology of testimony, CAJ Coady puts forth a quite restrictive view of what he believes constitutes testimony (let this be the 'narrow view'). ${ }^{19}$ For Coady, 'S testifies by making some statement $p$ if and only if: (i) S's stating that $p$ is evidence that $p$ and is offered as evidence that $p$; (ii) $S$ has the relevant competence, authority, or credentials to state truly that $p$; and (iii) S's statement that $p$ is relevant to some disputed or unresolved question (which may, or may not be, whether $\mathrm{p}$ ) and is directed to those who are in need of evidence on the matter'. ${ }^{20}$

Although instructive, critiques argue that this construction of the concept of testimony confuses metaphysical questions (what is the nature of testimony?) with epistemological questions (what is the difference between good and bad testimonies?). ${ }^{21}$ According to these critiques, under Coady's narrow view we would need only to ask the former kind of questions, since a statement will not count as testimony 'unless it is evidence ${ }^{, 22}$ for the proposition that $\mathrm{p}$ (condition (i)). Thus, under this view, it would be impossible to have an unreliable testifier: a speaker would simply fail to testify if its utterance did not constitute evidence of the proposition being argued for (that $p$ ). ${ }^{23}$ Because of this feature, this view has been rendered as overly 'restrictive', since there are certain utterances that we would 'not' be willing to accept as sources of 'reliable' beliefs, but that we nonetheless would consider as testimonies. ${ }^{24}$ For instance, when speakers testify about unidentified flying objects (UFOs), spontaneous human combustion, and clairvoyantism.

On the other side of the spectrum from Coady are Elizabeth Fricker and Robert Audi who conceive testimony as 'tellings generally' with 'no restrictions either on subject matter, or on the speaker's

\footnotetext{
${ }^{19}$ For our purposes, it is interesting to notice that Coady starts his investigation of a more precise notion of testimony with the legal context of testimony, claiming that certain features of legal testimony have influenced philosophical discussions of the topic. (Coady, supra n 13, p. 26).

${ }^{20}$ Coady, supra n 13, p. 42. Here, following Brewer and Lackey, I ignore the differentiation that Coady makes between natural and formal testimony. Given that our interest is in legal settings, not much is lost by broadening the discussion to include both accounts of testimony.

${ }^{21}$ Lackey, supra n 14, p. 16.

22 According to Coady, the notion of evidence in condition (i) is similar to what Peter Achinstein (1978, 1983) named 'potential evidence'. In this sense, evidence requires the 'truth' of $e$ and an 'objective connection' between $e$ and $h$, where $e$ is the putative piece of evidence and $h$ is that for which it is evidence. However, it is important to notice that $e$ can be evidence for $h$ even if $h$ is false, since it is only required that there is an 'objective connection' between $e$ and $h$. Moreover, though $e$ must be true in order to be potential evidence, it cannot entail $h$; entailment is simply too good to be evidence. See Lackey, supra $n 14$, p. 15 .

${ }^{23}$ Related critiques can be made to conditions (ii). Even in the absence of relevant competence, authority or credentials, we can still consider certain utterances as testimonies, although not necessarily reliable sources of KJB.

${ }^{24}$ Lackey, supra n 14, pp. 15-19.
} 
epistemic relation to it' ${ }^{25}$ (let this be the 'broad view'). On this view, ' $S$ testifies that $p$ if and only if S's statement that $p$ is an expression of S's thought that $p$ '.

Such a view of testimony avoids the problems afflicting the narrow view. Under the broad view, a speaker can give a statement both without it constituting potential evidence, and without having the relevant competence to state truly that $p$. As a consequence, this view properly distinguishes between metaphysical and epistemological questions, leaving the refereeing between good and bad testimony to a subsequent exercise. ${ }^{26}$

However, the broad view suffers from the opposite problem: it is overly 'permissive', since it fails to recognize the distinction between entirely non-informational expressions and testimonies. For instance, so conceived, the broad view would consider as testimonies utterances neither offering nor taken as conveying information, such as thinking out loud while alone: 'It is cold!' Conversational fillers, and polite responses, also constitute examples. ${ }^{27}$ Certainly, there might be situations in which a statement like 'It is cold!' 'is' meant to convey information, such as when someone asks me about how the temperature is where I currently am. This could be understood as a case of testimony. But, if I am alone and say such a sentence to anyone but myself, we would have a hard time framing it as a case of testimony. So, the idea is not that such unpretentious utterances 'never' qualify as instances of testimony but only that they should not 'always' be considered as such.

Given the problems with both the narrow and the broad views, Peter Graham offers a middle-ground position, what might be called a 'moderate view' of testimony. According to Graham: ' $S$ testifies by making some statement that $p$ if and only if: (i) S's stating that $p$ is offered as evidence that $p$; (ii) $S$ intends that his audience believe that he has the relevant competence, authority, or credentials to state truly that $\mathrm{p}$; and (iii) S's statement that $\mathrm{p}$ is believed by $\mathrm{S}$ to be relevant to some question that he believes is disputed or unresolved (which may or may not be whether $\mathrm{p}$ ) and is directed at those whom he believes to be in need of evidence on the matter' ${ }^{28}$

This account is broad enough to avoid some of the difficulties of Coady's narrow account, for instance, by not requiring that the statement in question actually constitutes evidence (but only that it be offered as such), and by requiring merely that $S$ intends that her audience believe that she has the proper and relevant credentials to affirm truly that $p$. At the same time, it is narrow enough to place restrictions on statements so that non-informational utterances are ruled out, namely condition (iii). However, the moderate position is not without its problems.

One of them concerns condition (ii) ${ }^{29}$ It must not be the case that, in testifying, one must intend his/ hers audience to take one as having the relevant competence, authority or credentials to state truly that

${ }^{25}$ Elizabeth Fricker, Critical Notice, 104 MIND, n. 414, pp. 393-411, 1995, pp. 396-7; and Robert Audi, The Place of Testimony in the Fabric of Knowledge and Justification, 34 AMERICAN PHILOSOPHICAL QUARTERLY, n. 4, pp. 405-422, 1997. In a similar vein, Emest Sosa defends 'a broad sense of testimony that counts posthumous publications as examples ... [It] requires only that it be a statement of someone's thoughts or beliefs, which they might direct to the world at large and to no one in particular'. (Lackey, supra n 14, p. 20, citing ERNEST SOSA, KNOWLEDGE IN PERSPECTTVE: SELECTED ESSAYS IN EPISTEMOLOGY, 1991, p. 219).

${ }^{26}$ Lackey,supra n 14, pp. 20-21.

${ }^{27}$ See Ibid p. 21. This point is also noticed by Peter Graham, who says, 'it should be noted that mere statements are not testimony. Saying 'It is a nice day' is not usually taken as testimony about the weather (though it is when said by the weatherman). Repeating what you have already said over and over does not count as testimony either, unless you have forgotten each previous utterance'. (Peter J. Graham, What Is Testimony?, 47 THE PHILOSOPHCAL QUARTERLY, n. 187, pp. 227-232, 1997, p. 231).

${ }^{28}$ Graham, lbid p. 227.

29 BENJAMIN S.P. ALMASSI, EXPERT TESTIMONY AND THE SOCIAL TRANSMISSION OF SCIENTIFIC KNOWLEDGE, PhD Dissertation presented at the Department of Philosophy at University of Washington, 2009 , p. 05. 
p. John can give Mary testimony even on subjects about which he knows Mary doubts his expertise, even if he anticipates that Mary is more likely to fully reject his testimony. John can still try, and so can still testify.

Moving on, we get to Lackey's 'disjunctive view'. In her understanding, ' $\mathrm{S}$ testifies that $\mathrm{p}$ by making an act of communication a if and only if (in part) in virtue of a's communicable content (i) $\mathrm{S}$ reasonably intends to convey the information that $\mathrm{p}$; "or" (ii) a is reasonably taken as conveying the information that $\mathrm{p}^{,{ }^{30}}$

The distinctiveness of Lackey's view is marked by the fact that she recognizes the distinction between testimony as an intentional act on the part of the speaker 'or' testimony as a source of $\mathrm{KJB}$ for the hearer. ${ }^{31}$ Also, Lackey's view is distinct for its reliance on the concept of conveying information, instead of focusing on the notion of offering evidence, as do the previous views, notably the narrow and the moderate views.

Finally, we have Almassi's 'audience-oriented' view. In his $\mathrm{PhD}$ dissertation, Almassi constructed the following conception of testimony: ' $S$ testifies to $p$ just in case she asserts $p$ with the intention that her listeners will take her to be offering her testimony of $p$ as evidence for $p$ '. He names his conception as 'audience-oriented' because it 'take[s] as necessary that the speaker's utterances are intended to be given to a listening (or reading) audience'. ${ }^{32}$

Almassi takes his view to be superior to Lakey's because he believes we can learn from others' words even when we are not learning from their testimony, as is the case when we read someone's private diary. Usually, a private diary is not written with an intended audience, thus, Almassi suggests, the writer is not offering her expressions as reasons for others to believe the content of her thoughts, and thus is not giving testimony. ${ }^{33}$ In this sense, a posthumously published diary (not written for an audience) would count as testimony in Lackey's disjunctive view, but not in Almassi's audienceoriented view.

2.2.2 Epistemic justification of testimony. Another interesting discussion concerning the epistemological features of testimony is related to its 'justification'. The two central views found on this topic in the literature are 'reductionism' and 'non-reductionism'.

According to reductionism, testimony derives its epistemic integrity from being reducible to other familiar sources of KJB, such as memory, perception and inference. Consequently, reductionists require that hearers must possess non-testimonial positive reasons in order to accept the testimony of speakers with justification or warrant.

Some proponents of the reductionist position are committed to what can be framed as the 'transmission thesis' ${ }^{34}$ That is the idea that KJB is acquired through testimony when speakers 'transmit' their beliefs, to their corresponding hearers, alongside the epistemic properties such beliefs possess. According to a central component of this thesis, hearers can acquire knowledge on the basis of the

\footnotetext{
${ }^{30}$ Lackey, supra n 14 , pp. 35-36.

${ }^{31} \mathrm{Ibid}$ p. 27. In her account of testimony, 'hearers need positive reasons in order to acquire testimonial knowledge, [...] and testimony is construed as an irreducible source of knowledge'. In doing so, she aims to avoid both the objections often directed to both reductionists (underestimating or devaluing the importance of testimony) and non- reductionists (gullibility and intellectual irresponsibility).

${ }^{32}$ Almassi, supra n 29 p. 03.

${ }^{33}$ Ibid p. 05.

${ }^{34}$ Lackey, supra n 14, pp. 1-3.
} 
testimony of speakers only if the speakers themselves possess the knowledge in question. An analogy generally given to express this idea is of the bucket brigade. ${ }^{35}$

Imagine the following situation: each individual in a bucket brigade must have a bucket full of water in order to pass it to the next person, so that there must be at least one individual who ultimately acquires the water from an independent source. The analogy is that each speaker in the chain must have $\mathrm{KJB}$ in order to pass it to the next person, so that there must be at least one individual who ultimately acquires the KJB from a source other than testimony.

In contrast, non-reductionists defend that testimony can be an independent source of KJB. Accordingly, hearers would not need to possess appropriate non-testimonial reasons for testimonial justification or warrant. They match testimony to traditional epistemic sources such as sense perception, memory and reason. Non-reductionist authors argue that the transmission thesis is misguided and that there are various ways in which hearers can acquire KJB from speakers who do not themselves possess KJB about the proposition in question. They argue that unreliable believers can be reliable testifiers.

On the one hand, because reductionists hold that KJBs based on testimony must be reducible to other sources of knowledge, this position is condemned to underestimating the importance of testimony. On the other hand, because non-reductionists endorse the epistemic independence of testimony from other sources of $\mathrm{KJB}$, this position is criticized for allowing for naivety and epistemic irresponsibility.

Arguing against reductionist positions, Coady, for instance, holds that it is not the case that one can rely on one's own experience to empirically check whether all testimonies we hear are reliable, given that we rely on too many testimonies, while having too little personal observation base. ${ }^{36}$ Coady seems to be advocating against what we can call 'strong reductionism', a position that holds that we have to be able to reduce 'all' testimonial KJB to more fundamental, and less problematic, epistemic sources and principles such as perception, memory and inference. ${ }^{37}$

However, Ficker argues that Coady fails to acknowledge the possibility that we might hold a form of 'weak reductionism', which holds that we have to be able to reduce 'some' (but not all) testimonial $\mathrm{KJB}$ to more fundamental and less problematic epistemic sources and principles such as perception and memory. ${ }^{38}$

Certainly, in some situations, we seem to have no choice but to accept much testimonial information we obtain. Take, for instance the fact that children have to accept passively much testimonial information given to them, such as acquisition of language and concepts from parents, teachers and peers. ${ }^{39}$ However, authors like Ficker argue that once we reach an 'epistemic age', we would not only be able to, but 'should' adopt a permanent critical attitude toward testimonies. ${ }^{40}$

The failure to acknowledge such a distinction, for Ficker, accounts for a weakness in Coady's position. When Ficker argues that we should hold such critical position toward testimonies, we can presume, that she supposes that we actually can do it (ought implies can). If this is the case (as I believe it is), her position is exactly what Coady is arguing 'against'.

${ }^{35}$ Ibid p. 47.

${ }^{36}$ Coady, supra n 13, pp. 79-100.

${ }^{37}$ This position is seems to be held, for instance, by David Hume.

${ }^{38}$ Ficker, $I d$.

${ }^{39}$ Ficker, Id., p. 401. But see Lackey, supra n 14, chapter 07. This argument was already present in later Wittgenstein (see LUDWIG WITTGENSTEIN, PHILOSOPHICAL INVESTIGATIONS, 1953).

${ }^{40}$ Ficker, Id. 
There is no reason to restrict Coady's scepticism about our capacity to empirically check whether a testimony is reliable to our young ages. Even as adults, it is reasonable to presume that most of us, most of the time and in most situations do not posses the means, the time or the expertise to empirically check whether a testimony is reliable.

Furthermore, Coady's position is particularly interesting for legal settings (our main concern here). However optimistic we may be about the possibility of rational inquiries into testimonies in our personal and professional lives, when considering legal settings, this proposition becomes much harder to defend. Legal settings suffer from certain constraints (e.g. time, resources, institutional, procedural) that make a critical attitude extremely difficult to maintain, to a point where we should become sceptical about it ever coming into being.

One might respond that courts already possess an edge of institutional apparatus and know-how for promoting this kind of critical attitude (especially in adversarial systems) given the presence of practices such as cross-examination, discovery, the incentive structure of the parties to engage in further investigation and refutation of the other party's claim, etc. This might be so, but I believe this critique misses the point.

My scepticism on this particular point is focused on the position of the legal decision-maker. To some extent judges, and even less juries, are not able to adopt a critical attitude towards testimonies at lawsuits. When assessing each witness's testimony, they (judges and juries) are 'restricted' to the testimonies and other sets of evidence presented in court by both parties, together with their previous set of beliefs about the world. ${ }^{41}$

It is a significant leap of faith to presume that the structures and incentives behind the adversarial system of trials provide sufficient conditions for legal decision-makers to check empirically whether the reasoning supporting testimonies is empirically reliable. This is a leap we should be at least cautions to make.

This scenario gets further complicated when we acknowledge that there are special kinds of testimonies, such as scientific expert testimony, that make it even more difficult to see how reliability could ever be checked empirically by non-expert legal decision-makers who are constrained by epistemic limitations, explicitly, their lack of expertise.

One possible strategy is the hearer of a testimony relying on the testifier's sincerity and competence. In some cases, one could argue that we are epistemologically justified in presuming both sincerity and competence, 'in the lack of proof of the contrary'. ${ }^{42}$ Sincerity, in those cases, would be possible to be assumed in the absence of signs of its lack, provided that 'the hearer must always be scrutinizing the speaker for telltale signs of its absence'. ${ }^{43}$ According to Fricker, in such view, a presumption of

\footnotetext{
41 By this, I mean that judges and juries do not have all resources and opportunities necessary to adopt such critical instances available to them during trial. For instance, due to specific normative concerns, judges are obliged to stay restricted to the facts and claims presented during the case. Further constraints found in law trials include limited resources, workload and time.

42 The view in question is represented, for instance, by Ficker, Id., Tyler Burge (Tyler Burge, Content Preservation, 102 THE PHILOSOPHICAL REVIEW, n. 4., pp. 457-488, 1993) and Richard Foley (Richard Foley, How Should Future Opinion Affect Current Opinion?, 54 PHILOSOPHY AND PHENOMENOLOGICAL RESEARCH, n.4, pp. 747-766, 1994) who hold that the bare assertion of a claim by a speaker gives a hearer prima facie reason to accept it, quite independently of anything the hearer might know or justifiably believe about the speaker's abilities, circumstances, or opportunities to have acquired the claimed piece of knowledge. Burger goes as far as developing what he called the 'acceptance principle', according to which '[a] person is entitled to accept as true something that is presented as true and that is intelligible to him, unless there are stronger reasons not to do so'. (Burge, Ibid p. 467).

${ }^{43}$ Ficker, Id.
} 
competence 'may be assumed as the default setting'. ${ }^{44}$ But Fricker herself exposes how fragile and limited this presumption is.

To the presupposition of sincerity and competence in the absence of evidence to the contrary, Fricker argues that ' $[t]$ he proportion of utterances which are made by speakers who are either insincere or incompetent is far too high for this to be an attractive policy'. ${ }^{45}$ As Brewer points out, ${ }^{46}$ perhaps it is alertness to this difficulty that leads Fricker to make the claim that 'the key to the epistemology of testimony is: disaggregate [. . .] both regarding the question of whether and when we may rightly trust without evidence, and regarding the empirical confirmation of speakers' trustworthiness' ${ }^{47}$ This disaggregation does not solve all of our problems. ${ }^{48}$

As a general mindset to be held as we engage in the project of investigating the epistemic integrity of testimony, this maxim seems hard to be refuted and, as we will later see, it might be quite helpful. $^{49}$

The topic of how to deal with scientific expert testimony was at the heart of the 1993 U.S. Supreme Court case Daubert v. Merrell Dow Pharmaceuticals, ${ }^{50}$ and its progeny. ${ }^{51}$ The particular issue at the Daubert trilogy was how to state certain normative criteria according to which federal judges can properly access scientific information and perform their role of 'gatekeepers', preventing 'junk science' from getting into the decision-making process. ${ }^{52}$ To guide that inquiry, the Court overruled a 70 -year precedent ${ }^{53}$ and defined that, under Federal Rule of Evidence 702, it is the judge's duty to determine whether an expert's testimony rests on a reliable foundation. ${ }^{54}$ This assessment could be

${ }^{44}$ Ficker, Id.

${ }^{45}$ Brewer, supra n 1, p. 1607, citing Ficker, Id., p 75.

${ }^{46}$ Brewer, supra n 1, p. 1608.

${ }^{47}$ Ficker, Id., p. 407.

${ }^{48}$ E.g. can testimonies be reliable sources of $\mathrm{KJB}$ ? Is there some way non-experts can verify the reliability of the testimony of experts?

${ }^{49}$ Brewer, supra n 1, p. 1608.

${ }^{50}$ Daubert v. Merrell Dow Pharmaceuticals, 509 U.S. 579 (1993).

${ }^{51}$ When I refer to Daubert's progeny, I mean the two subsequent cases, General Electric Co. v. Joiner 522 U.S. 136 (1997) and Kumho Tire Co. v. Carmichael 526 U.S. 137 (1999), in which the Supreme Court broadened the reach of trial judges under the Daubert ruling by allowing them to consider conclusions instead of only methodological issues, and extending their gate-keeping function to also include 'non-scientific evidence', To the same extent, when I refer to the Daubert Trilogy, I am referring to the three cases (Daubert, Joiner and Kumho) altogether.

${ }^{52}$ A federal judge's task according to the Daubert decision is to act as 'an external observer comparing the expert's methodologies with what appears to be acceptable'. (DAVID L. FAIGMAN ET AL ., MODERN SCIENTIFIC EVIDENCE , 2009, p. 708). However, according to David Sklansky, 'a review of caselaw after Daubert shows that the rejection of expert testimony is the exception rather than the rule'. (DAVID ALAN SKLANSKY, EVIDENCE : CASES, COMMENTARY, AND PROBLEMS , 2008, p. 513.)

${ }^{53}$ In Daubert, the Supreme Court changed the rules for admission of scientific expert evidence in federal courts, setting aside the so-called Frye test adopted 70 years earlier by the D.C. Court of Appeals (Frye v. United States, 293 F. 1013 (D.C. Cir. 1923)), by holding that the Federal Rules of Evidence enacted in 1975 had superseded Frye. Kaye et al argue that Daubert is "neither uniformly stricter nor invariably weaker than Frye. It's emphasis is different $[. . . J$ and its impact depends on how the concept of validity and fit are applied." (DAVID KAYE ET AL, THE NEW WIGMORE : A TREATISE ON EVIDENCE (EXPERT EVIDENCE), 2011, p. 301). For a chart illuminating some differences between both precedents, see Michael J. Saks, Merlin and Solomon: Lessons from the Law's Formative Encounters with Forensic Identification Science, 49 HASTINGS L.J. $1069,1078,1998$. For a very interesting work on the social and racial circumstances in which the Frye case was decided, see Seán That O'Donnell, Courting Science, Binding Truth: A Social History.

${ }^{54}$ Daubert, supra n 50, p. 597. 
made through the following criteria: ${ }^{55}$ (i) falsifiability; (ii) peer review; (iii) error rate; (iv) professional standards; and (v) general acceptance. ${ }^{56}$

These procedural manoeuvres were governed by the driving belief that scientific criteria should determine the assessment of science in legal settings. ${ }^{57}$ In this sense, it is usually said that the Daubert trilogy required judges to think like scientists when deciding on the reliability of any given scientific evidence. ${ }^{58}$ However, much less commonly observed is the fact that judges, in practice, gained wide latitude to decide themselves how scientists think in a way that strengthens courts' institutional power. ${ }^{59}$

The preceding discussion leaves us with at least one clear conclusion: it is simply not reasonable to assume that 'all' testimonial KJB shares the same virtues. At a minimum, there are special kinds of testimonies that we would have a harder time framing as sources of KJB for non-experts.

I will stop this discussion here. Further inquiry into whether testimony can (or does) yield $\mathrm{KJB}$ is out of the scope of this article. Our purpose in this section was only to present part of the existing debate with the hope that it will shed light on our discussion in Section 3.

\subsection{Epistemic deference}

After introducing some theoretical insights concerning the epistemology of testimony, I now turn to the idea of 'epistemic deference'. The underlying notion in the idea of epistemic deference is that many times, we do not possess the means, the time or the expertise to go around gathering direct empirical evidence for our KJB. Thus, we would have to 'defer' to others to convey information to us.

\footnotetext{
55 The majority's opinion explicitly mentions how these criteria are mainly exemplificative, there are neither exhaustive nor strictly necessary: 'many factors will bear on the inquiry, and we not presume to set out a definite checklist or test'. (Daubert, Ibid p. 593). For the qualification of each criterion, see Daubert, Ibid pp. 591-595.

${ }^{56}$ Different authors have argued for different criteria. See, for instance, The Federal Guidelines, from administrative agencies, such as the Environmental Protection Agency (EPA), and from authors like Larry Laudan, Michael Pardo, and Erica Beecher-Monas. See respectively, LARRY LAUDAN, TRUTH ERROR AND CRIMINAL LAW: AN ESSAY IN LEGAL EPISTEMOLOGY, 2008; Michael S. Pardo, The Field of Evidence and the Field of Knowledge, 24 LAW AND PHILOSOPHY, 2005; and ERICA BEECHER-MONAS, EVALUATING SCIENTIFIC EVIDENCE: AN INTERDISCIPLINARY FRAMEWORK FOR INTELLECTUAL DUE PROCESS, 2006.

57 This corresponds to the law's 'deferential' position towards expert authority, which contrasts with an alternative 'educational' position, which holds that the proper role of experts to explain their discipline to the fact finder and convince him of the truth-value of his claims. See Ronald J. Allen \& Joseph S. Miller, The Common Law Theory of Experts: Deference or Education?, 87 NorTh WeStern UnIVERSTTY Of LAW REVIEW. 1131 (1993). Also, see Frederick Schauer, Can Bad Science be Good Evidence? Lie Detection, Neuroscience and the Mistake Conflation of Legal and Scientific Norms, 95 CORNELL LAW REVIEW $06,1191,2010$, arguing that the 'ultimate normative and institutional question of whether and when, if at all, a given degree of validity or reliability is sufficient for this or that legal or forensic purpose is a legal and not a scientific question'. (at 02). See also Dale A. Nance, Reliability and the Admissibility of Experts, 34 SETON HALL LAW REVIEW 191, 203, 2003 (arguing for use of legal standards in evaluating scientific expertise); David L. Faigman et al., SCIENCE IN THE LAW: STANDARDS, STATISTICS AND RESEARCH ISSUES § 1-3.5.1, p. 43, 2002 (determining value of scientific expert opinion 'is a matter of policy, not science'), and Brain Leiter, The Epistemology of Admissibility: Why Even Good Philosophy of Science Would Not Make for Good Philosophy of Evidence, BYU LAW REVIEW 803, 1997.

58 KENNETH R. FOSTER, PETER W. HUBER JUDGING SCIENCE: SCIENTIFIC KNOWLEDGE AND THE FEDERAL COURTS, 1999

${ }^{59}$ These remarks should not be misunderstood. They are not meant to defend the purity of scientific claims against strategic (mis)use by judges. Quite the contrary, they are meant to demonstrate that scientific constructions are not merely transformed once they enter the closed operational network of legal discourse in the form of evidence; they are constituted anew in the legal process with borrowed authority from science. What happens to these constructions is no longer in the scientists' hands. Their creation, stabilization, and diffusion is the job of legal professionals. See Gunther Teubner, How the Law Thinks, 23 LAw \& Society Review n. 5, 1999, p. 750 and Sheilla Jasanoff, Science at the Bar, 1995.
} 
In arguing for the rationality of epistemic deference, ${ }^{60} \mathrm{John}$ Hardwig starts his seminal 1985 paper by affirming that he finds himself believing all sorts of things for which he does not possess evidence. The major difficulty in recognizing that we have no evidence for the veracity of some of our beliefs is that this could lead us to conclude that those beliefs are irrational or, at least, non-rational. But is that really the case? Are there any good reasons for holding beliefs, reasons not merely reducible to having evidence for the truthiness of those beliefs? This is the question Hardwig poses himself, and is an important one for our purposes.

Hardwig suggests that one 'can' have good reason for holding a belief if one has good reason to believe that 'others' have good reason to hold it. Suppose that an individual, A, has evidence for believing that $p$, but a second individual, B, does not. However, suppose also that $\mathrm{B}$ has good reason to believe that $\mathrm{A}$ has good reason to believe that $\mathrm{p}$. Based on this scenario, Hardwig questions, are we not allowed to say that $\mathrm{B}$ does, ipso facto, have good reason to believe that $\mathrm{p}$ ? $^{61} \mathrm{He}$ answers affirmatively.

For Hardwig, B is not only allowed to hold the belief that p, but also that is B's 'rational' strategy. The idea is that epistemic deference might be more rational than necessarily seeking epistemic autonomy at all costs, since 'if I were to pursue epistemic autonomy across the board, I would succeed only in holding relatively uninformed, unreliable, crude, untested, and therefore irrational beliefs' ${ }^{62}$ Thus, rationality sometimes would require 'refusing to think for oneself'. ${ }^{63}$

As expressed, Hardwig's position seems to be that a hearer's good reason to believe that an expert speaker has good reason to believe that $p$, based on the speaker's testimony that $p$, does 'not' constitute 'evidence' for $\mathrm{p}^{64}$ This has been called a 'non-evidence account of testimony' ${ }^{65}$ The idea is that although $B$ has good reason to believe that $p$, this reason does not count toward establishing the truth of $\mathrm{p}$; it counts only toward establishing that $\mathrm{A}$ knows, or has reason to believe, what $\mathrm{A}$ is talking about.

Moreover, according to Hardwig, when a non-expert relies on an expert, that deference is 'blind'. But what makes this deference blind? Recall our above-mentioned scenario of individuals A and B. Hardwig argues that B's belief in $p$ is blind because B has no 'access' to A's reasons for $p$, which constitutes the evidence for his statement that $\mathrm{p}$. Thus, while A would have evidence for $\mathrm{p}$, B would

\footnotetext{
${ }^{60}$ It should be noted that Hardwig uses the terminology of 'epistemic dependence', instead of 'epistemic deference', however, for sake of coherence only, I will maintain throughout the analysis a consistent use of 'epistemic deference', for I believe both expressions convey similar ideas for my purpose here.

${ }^{61}$ This position implies that Hardwig is also committed to the position that $\mathrm{B}$ can have good reason to believe that $\mathrm{p}$ even when $p$ is false and even when expert A does 'not' have good reason to believe that $p$. Thus, we can see that Hardwirg defends a fallibist conception of knowledge.

62 John Hardwig, Epistemic Dependence, 82 THE JOURNAL OF PHILOSOPHY, n. 7, pp. 335-349, 1985, p. 340.

${ }^{63} \mathrm{Ibid}$ p. 336. It is interesting to highlight that Hardwig also demonstrates scepticism about non-experts' capacity to make justified decisions in face of conflicting expert testimonies. According to him, the non-expert must either suspend belief or arrive at belief on some admittedly non-rational basis.

${ }^{64}$ This view turns on delicate epistemological issues involved in clarifying the concept of evidence. Hardwig's conception of evidence relies on the following ideas: (i) although A's evidence counts toward establishing the truth of $p$, the case for $p$ is not stronger after B discovers that $A$ has this evidence than it was before B found out about A and A's reasons; (ii) the chain of appeals to authority must end somewhere, and, if the whole chain of appeals is to be epistemically sound, it must end with someone who possesses the necessary evidence, since truth claims cannot be established by an appeal to authority; (iii) evidence that $p$ counts against evidence that not $p$. But consider a case of conflicting experts: $A$ who has evidence that $p$ and $C$ who has evidence that not $p$. In such a case, if B believes that $p$ only because he believes that $A$ has good reasons to believe that $p$, B's reasons do not count against C's; only A's do.

${ }^{65}$ See Almassi, supra $\mathrm{n} 29$.
} 
only have evidence of A's belief, but B would not have evidence himself for $\mathrm{p} .{ }^{66}$ Hardwig then argues that B's testimonial reason for belief, is 'a very odd kind of good reason for belief: a reason that does not constitute evidence for the truth of $\mathrm{p}^{\prime}$. $^{67}$

This position creates a dichotomy between relying on testimony and assessing evidence. To say that $B$ in our example has 'no' evidence for $p$ is equivalent to saying that, for most of our beliefs, none of us have anything that counts toward the truth of $p$ against the various backgrounds of our wide ranging beliefs.

But it does not have to be that way. We can come to the conclusion that an expert's testimony that $p$ 'does' count as evidence for the proposition that $p$ for the hearer.

Consider the case of belief acquired through the use scientific instruments. If A were instead some widely held reliable measuring device such as a mercury thermometer, most of us would be willing to hold the position that the instrumental output of A gives its user B 'evidence' of the proposition the instrument is designed to yield. But why should things be so different when $\mathrm{A}$ is human? ${ }^{68}$

The idea is not to hold that testimonial justification is in each and every way necessarily equivalent to instrument-based justifications, but only that there is no a priori reason to render human testimonial inferences as always necessarily epistemically inferior to any kind of mechanical output. Possibility of error exists in both. Neither is $100 \%$ certain, nor should we require each to be so in order to regard it as evidence for our KJBs.

Someone might argue that the difference between human testimonies and mechanical outputs would then be not of 'kind' but of 'degree'. To the extent that mechanical outputs would be much more reliable than human testimonies, we could render the former a superior epistemic position. But there is not a clear reason why we should render instruments as always necessarily yielding superior, more reliable evidence then human testimonial. If our problem is distrust in others, we should highlight the not-so-obvious insight that instrument measurement requires a great dose of human manipulation at various levels. Conceiving of the instrument, constructing it, calibrating, setting up the measurement, recording the result, etc. All these are human activities, to which, if we were coherent, our scepticism towards individuals should be applied.

But that is not all. Human influence in instrument measurement goes well beyond the manipulation of the material itself. Measurements (or any king of experiment) are not undertaken in a void of ideas. Quite the contrary. What to measure, how to do it, when, all these are previous 'choices' made by humans, that in turn rely on a great deal of previous and background assumptions held by the person (or group) responsible. ${ }^{69}$

Given the inescapability of human influence in scientific practice, there is no a priori reason why we should assign mechanical measurement a necessarily higher degree of epistemic reliability than testimonial evidence.

On this point, one could argue that there is a difference between mechanical measurement and testimonial measurement that is vital to this discussion, namely, the fact that a non-expert could check

\footnotetext{
66 Recall that based on the foregoing discussion about reductionists and non-reductionists positions regarding the epistemic justification of testimony, Hardwig's position would constitute a clear cut example of reductionists. That is clear when, for instance, he says: 'The chain of appeals to authority must end somewhere, and, if the whole chain of appeals is to be epistemically sound, it must end with someone who possesses the necessary evidence, since truth claims cannot be established by an appeal to authority, nor by investigating what other people believe about them.' (Hardwig, supra n 62, p. 337).

${ }^{67}$ Ibid p. 337.

68 Almassi, supra n 29, p. 40.

${ }^{69}$ Shapin, supra n 16, chapter 01 .
} 
for himself the result of measurement in order to decide if it does indeed constitute evidence for his $\mathrm{KJB}$. But in the case of the testimonial evidence, that would not be possible. The individual would have to rely on trusting the person conveying the information.

Again, this critique misses the point. As mentioned above, a necessary part of any measurement is carefully reading and interpreting the results. This requires a given expertise that is most likely to be simply inaccessible to the non-expert in question, to the extent that having access to the results of the measurement will not make much difference. Think of the case of statistical analysis, or data requiring the use of a microscope, to name a few.

Hardwig's position has also been charged with incoherence ${ }^{70}$ This critique assumes that Hardwig's claim presupposes the very distinction between expertise and non-expertise that Hardwig himself undercuts in other parts of his essay. If the critics are right, his analysis of epistemic dependence assumes that there are intellectually independent experts for the rest of us to rationally depend on, a view incoherent with the rejection of intellectual independence for non-experts and experts alike, which Hardwig explicitly holds.

Take, for instance, the following statement:

'How can $B$ have good reasons to believe that $A$ has good reasons to believe that $\mathrm{p}$ when

$B$ does not himself have evidence that $\mathrm{p}$ ? It's easy - B has good reasons to believe that

A has conducted the inquiry necessary to have evidence for believing that $\mathrm{p}^{\text {' }}{ }^{1}$

This critique relies on Hardwig's explicit commitment to the 'no-evidence thesis'. ${ }^{72}$ For him, (recall our example) B's reasons to believe that expert $A$ has good reason to believe $p$ derives from the presumption that 'A has conducted the inquiry necessary to have evidence for believing that $p$ '. ${ }^{73}$ Given this view, eventually there would have to be an individual to conduct the necessary inquiry for evidence for $\mathrm{p}$, who could not 'simply' rely on the testimony of other experts. ${ }^{74}$

To better see this, let us elaborate on our example with individuals A and B. Imagine a new scenario where A's colleague $C$ is the one who has 'evidence' (in Hardwig's sense) for the proposition that $\mathbf{p}$. Even if $A$ has good reason to believe that $C$ has good reason to believe $p$, the 'no-evidence thesis' would entail that $\mathrm{A}$ has no evidence for believing $\mathrm{p}$. This puts layperson $\mathrm{B}$ in an awkward position.

In our elaborate scenario with individual $C$, if we were to hold Hardwig's views, A does not have evidence for all her KJB. Almassi elaborates on this point:

' $[\mathrm{s}] \mathrm{o}$ either $\mathrm{B}$ must believe a fiction in deferring to A on matters within her domain of expertise; or B must rationally decline to defer to A on such matters; or B must somehow distinguish those expert-knowledge claims A knows independently (thus yielding evidence) from those expert-knowledge claims A knows through rational epistemic dependence on fellow experts (yielding no evidence). The last option would be appealing, if possible, but then the layperson B can rarely be so discerning. ${ }^{75}$

\footnotetext{
${ }^{70}$ Stella Gaon and Stephen P. Norris, The Undecidable Grounds of Scientific Expertise: Science Education and the Limits of Intellectual Independence, 35 JOURNAL OF PHILOSOPHY OF EDUCATION, n. 2, pp. 187-201, 2001.

${ }^{71}$ Hardwig, supra n 62, p. 337.

72 Almassi, supra n 29, p. 55.

${ }^{73}$ Hardwig, supra n 62, p. 337.

${ }^{74}$ This discussion is similar to the one about the bucket brigade above.

75 Almassi, supra n 29, pp. 56-57.
} 


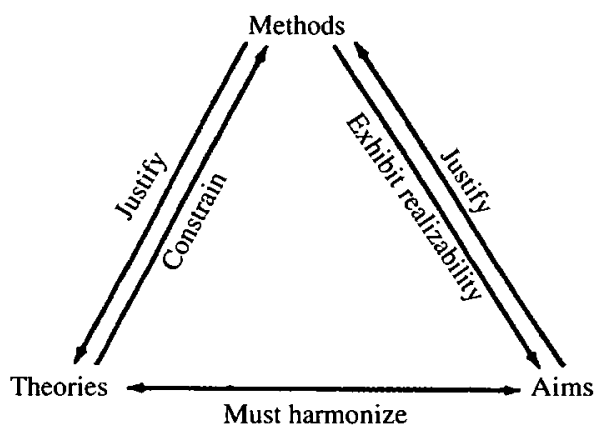

Fig. 2. (Larry laudan, science and values: the aims of science and their role in scientific debate (1984) p. 63).

Thus, Hardwig would implicitly assume epistemic independence of experts ${ }^{76}$ even as he insists that experts frequently must act like laypeople within their own field, as his critics charge. But this is only so long as he keeps the no-evidence thesis.

This problem can be avoided if we allow testimony to be understood as evidence. This is so because experts could, then, be recognized as having 'evidence' for their beliefs through individual inquiry, 'or' through informed trust in colleagues. In this sense, admitting testimony as evidence allows us to conclude that epistemic interdependence among experts need 'not' undermine the reliability of their beliefs and claims.

Let us end this discussion here before we are lost in further digressions. Our purpose in this section was to present a particular treatment of the idea of epistemic deference, confident that this might help our inquiry in Section 3.

\subsection{Expertise}

We now move to what is the last philosophical discussion that constitutes a necessary step for us to get into our discussion about the problems of conflicting expert testimonies and proposed solutions. This is the discussion about the concept of 'expertise'. Here, I am mainly interested in questions such as what does it mean to be an expert?; and what features differentiate an expert from a non-expert?

I first turn to Scott Brewer's analysis of expertise. Brewer's work relies heavily on Larry Laudan's work on scientific reasoning. ${ }^{77}$ In his 1984 book, Laudan argues for a model of scientific reasoning that identifies three different levels of analysis: the factual, the methodological and the axiological. At the factual level, we find 'all manner of claims about what there is in the world, including theoretical and unobservable entities' ${ }^{78}$ At the methodological level, we find the methods and rules about methodology that scientists share. Lastly, the axiological level concerns what Laudan calls the "cognitive aims' of science. ${ }^{79}$

\footnotetext{
${ }^{76}$ Hence, fall in the so-called 'Paradox of expert independence'.

${ }^{77}$ See Brewer, supra n 1, p. 1572. The main source of this analysis in Laudan's work is LARRY LAUDAN, SCIENCE AND VALUES: THE AIMS OF SCIENCE AND THEIR ROLE IN SCIENTIFIC DEBATE, (1984).

${ }^{78}$ Laudan, supra note 77 , p. 23.

${ }^{79}$ By cognitive aims, Laudan means an 'attribute [that] represents a property of theories which we deem to be constitutive of "good science"” (Laudan, supra note 77, pp. xi and xii, fn 2).
} 
Laudan argues that scientific justification cannot be adequately explained as a linear hierarchy in which a scientist justifies factual claims by strict reference to methods and justifies the choice of method by strict reference to axiological aims, while axiological aims are constrained by nothing in particular. ${ }^{80}$ Laudan argues that the three levels are constrained in a multi-directed way within holistic networks of aims, methods and factual beliefs. More than that, they are intertwined in relations of mutual dependency. Laudan represents this relationship, which he calls 'The Triadic Network of Justification', in Fig. 2.

Having provided a quick and rough overview of Laudan's main points, we only have one more step before turning to see how Brewer draws on Laudan's axiological structure to expand its insights to any intellectual discipline that has a 'distinct intellectual method'. This is the distinction between believing a person and believing a proposition. Brewer puts it in the following way: '[w]here $S$ is some speaker offering testimony that $\mathrm{P}$ and $\mathrm{H}$ is a hearer of that testimony, it is the distinction between $\mathrm{H}$ 's believing that $\mathrm{P}$ and $\mathrm{H}$ 's believing $\mathrm{S}$ that $\mathrm{P}^{\prime}{ }^{81}$

One of the arguments supporting this differentiation is the observation that the proposition 'that $p$ ' cannot serve as evidence for itself, without having us engage in circular reasoning. However, in the example of believing ' $S$ that $p$ ' it is the case that the 'testimony' of $S$ that $p$ might serve as evidence for $\mathrm{p}$ (under some conditions to be fulfilled depending on one's epistemological account of testimony). The simple recognition that sometimes we take claims to be trustworthy due to the speaker's reputation or credentials, whereas we would not otherwise, allows us to better see the distinction.

After this quick qualification, we can finally get to Brewer's account of expertise. He contends that an expert is a person who has, or is regarded as having, specialized training that yields sufficient epistemic competence to understand the aims, methods and results of an expert discipline. ${ }^{82}$ Conversely, the non-expert does not have the specialized training required to properly understand the aims, methods, and judgements of an expert discipline, 'or to be able critically to deploy those methods, in service of the discipline's aims, to produce the judgments that issue from the discipline's distinctive point of view' ${ }^{83}$

Brewer's idea of expertise is based on the notions of 'content- independence' and 'peremptoriness'. The idea is that for A to be considered an expert for B, B has to accept A's judgement as providing a 'significantly peremptory and content-independent reason for believing what A says'. ${ }^{84}$

Thus, a non-geneticist does not need first to check the propositions the geneticist defends as true, only then to decide whether to defer to that geneticist about the truth of her proposition. To hold such a requirement would entail the 'negation' of the geneticist's expertise.

He develops it the following way:

'[f]or A to be an epistemic authority for B on some subject matter, B must believe that A has some superior knowledge, intelligence, or wisdom which makes it reasonable to believe that what A says on that subject is more likely to be true than the results reached by $\mathrm{B}$ through $\mathrm{B}$ 's independent investigations'. ${ }^{85}$

\footnotetext{
${ }^{80}$ Laudan, supra note 77 , pp. $23-41$. Here, it is interesting to notice that in developing this view, Laudan is arguing against visions of the progress of science that tend to focus solely either on the agreement or disagreement making process of scientists.

${ }^{81}$ Brewer, supra n 1, p. 1583.

82 Ibid p. 1589.

${ }^{83}$ Ibid p. 1589.

${ }^{84}$ Ibid p. 1586.

85 Ibid p. 1586.
} 
Here, another minor qualification is necessary. Expertise is to be considered not an all-or-northing rigid status, but instead as a matter of 'degree' ${ }^{86}$ There is simply no watermark separating expertise from non-experts. To the same extent, not all experts are equally competent in their respective domains nor all non-experts equally incompetent with regard to a specific specialized domain.

This qualification is important when acknowledging epistemic deference between experts within the same domain of expertise. For instance, one physicist specializing in quantum mechanics might defer to other physicist specializing in thermodynamics. Furthermore, a quantum mechanics physicist might even defer to another quantum mechanics physicist when constructing his working assumptions. This kind of deference among experts is ubiquitous, and even necessary in scientific practice. $^{87}$

In any case, the hearer (either the 'expert' or the 'non-expert') must be capable of very superficially policing whether the speaker's utterances are within what the former takes to be the epistemic boundaries of the expertise of the latter. The police concern is a thin line, allowing us to make sure we rule out 'clearly wrong' cases, such as when a geneticist tries to use his position as an expert in genetics to argue for the reliability of his claims about how super string theory leads theoretical physics astray. Certainly, the boundary here will be fuzzy and subject to modification. But as Brewer nicely states, ' $[\mathrm{t}]$ he price of rational deference is eternal vigilance' ${ }^{88}$

Brewer's account of expertise is closely related to Alvin Goldman's. For Goldman, expertise involves holding and rightly employing data and methods of a given domain of expertise, and properly performing operations on this information. ${ }^{89}$ This would also include having the epistemic capacity and means to form true beliefs relating to new problems brought to light in the relevant domain.

Both Brewer and Goldman are worried about constructing an idea of expertise that does not rely solely on 'possessing accurate information'. Both recognize that expertise has a comparative element. Experts are experts because there are non-experts. Like night and day, each is defined by reference to its counter-part. However, to the same extent, both Brewer and Goldman admit that expertise is not only a 'fully' comparative matter and both connect the idea with possessing a substantial body of truths in the target domain. If everyone only held false beliefs, and I held one true belief, I should not be understood as an expert based on that fact alone.

\section{Dealing with conflicting scientific expert testimonies}

\subsection{Novice/2-expert problem}

By novice/2-expert problem, ${ }^{90}$ I mean whether non-experts can make 'justified judgments' about the relative credibility of conflicting scientific experts testimonies. If so, when and how is this possible?

Before we begin, it might be worthwhile to make an important distinction. The novice/2-expert problem we are here concerned about is not to be confused with another related (yet different) problem that occupies the thought of many epistemologists, namely, the expert/expert problem. The latter involves the justified ways 'experts' should appraise the authority or credibility of rival experts. It raises questions such as: can there be such a thing as a 'reasonable disagreement'? If so, what should

\footnotetext{
${ }^{86}$ Ibid p. 1586. Goldman makes the same point in Alvin I. Goldman, Experts: Which Ones Should You Trust?, 63 PHILOSOPHY AND PHENOMENOLOGICAL RESEARCH, n. 1, pp. 85-110, 2001, p. 89.

${ }^{87}$ For the 'necessity' argument, see Shapin, supra $\mathrm{n} 16$.

${ }^{88}$ Brewer, supra n 1, p. 1587.

${ }^{89}$ Goldman, supra n 86.

90 The expression is from $/$ bid.
} 
each disagreeing expert do? A usual solution given by some philosophers is that in case of peer disagreement, one should give equal weight to the opinion of a peer and to one's own opinion. Thus, each side should 'calibrate' its previous position in light of the rival's. ${ }^{91}$ By contrast, in the novice/2-expert problem, the non-expert, by definition, is 'neither' in a position to evaluate the experts' propositions and arguments nor to 'calibrate' his own opinion.

Our problem unfolds along to the following lines: when experts testifying give contradictory statements (in the sense that it cannot be the case that both are truth), the non-expert must decide whom to believe (provided that he cannot suspend judgement). But how can a non-expert faced with conflicting expert testimonies (within the limits of a given discipline or in between disciplines ${ }^{92}$ ) about a relevant factual matter decide which expert to believe 'without' having the epistemic capacity to fully and properly assess the substantive arguments each expert offered?

Reproducing Goldman's analogy, the novice/2-expert problem can be fairly compared to the listener/eyewitness problem. ${ }^{93}$ Two witnesses assert they were present when the event (relevant for the factual inquiry in question) took place. The listener, however, was not present and does not hold any kind of prior belief about the event. The listener must make a decision about it, but he finds himself in the middle of two conflicting witnesses who claim to have superior knowledge of the 'relevant domain' (in this instance, having personal memory of visual perception of the event). How should the listener solve this puzzle? Who he should believe?

In theory, it may be possible for the listener to try to assess other pieces of relevant evidence in order to assess which eyewitness should be trusted. For instance, he might try to get evidence from third parties about whether both eyewitnesses actually were present at the place and time the relevant event took place, and saw it. Alternatively, the listener could try to assess whether both eyewitnesses have reasonably equal visual acuity, which may bear on their reliability. ${ }^{94}$ For our purposes, the question to pose is whether analogous methods of assessing credibility are available to non-experts trying to adjudicate between rival experts.

The problem we are interested in arises with the recognition, ex hypothesi, that the non-expert does 'not' have sufficient epistemic capacity in the relevant domain of expertise to properly, empirically assess the reasons supporting experts' testimonies. For reasons that will become clearer below, the legal system (and our society at large) places a high value on the rationality of authorities' decisions. This case is no different. We want the legal decision-maker to be able to make justified choices even in situations that involve questions related to domains in which he is not an expert.

In any possible solution the legal decision-maker might rely to resolve this puzzle, he will face the burden of bringing to light some plausible explanatory judgement about the relation between the chosen criteria and a putative higher level of confidence in one expert's side. ${ }^{95}$ As Brewer put it,

\footnotetext{
${ }^{91}$ For instance, PHILIP KITCHER, THE ADVANCEMENT OF SCIENCE: SCIENCE WITHOUT LEGEND, OBJECTIV. ITY WITHOUT ILLUSIONS, 1993 and Richard Feldman, Epistemological Puzzles About disagreement, in EPISTEMOLOGY FUTURES (Stephen Hetherington ed.), 2006. For a recent treatment of the topic see the collection of articles put forth by RICHARD FELDMAN AND TED WARFILED, DISAGREEMENT, 2010, in particular chapter 06: Thomas Kelly, PeerDisagreement and Higher-Order Evidence.

${ }^{92}$ Brewer refers to these as intra and extra-disciplinary conflicts, respectively. He also adds a 'real/implicit' dichotomy. See Brewer, supra $\mathbf{n} 1$.

${ }^{93}$ Goldman, supra n 86, p. 90 .

${ }^{94} \mathrm{~A}$ blind man testifying that he saw the event is certainly less reliable than a man who can see perfectly. This is an extreme example, but it fits to illustrate the point that reliability is relative and a matter of degree.

95 In fact, juries are not required by the legal system to explicitly articulate the justification for their decisions. However, American legal system (and others as well), seems to require that non-expert decision-makers chose between conflicting experts
} 
' $[t]$ hese problems that must be resolved in a way that is sufficiently epistemically warranted for practical (legal) purpose'. In other words, tossing a coin is out of the question.

At first sight, it might be extremely difficult to see how a non-expert could ever make such convincing decisions, without having epistemic competence in the relevant domain. In this sense, the non-expert's decision seems inevitably epistemically arbitrary.

This problem was described by Damaska, in the following terms:

'Instead of addressing divinity, we now appeal to scientific expertise. But how can our fact finders, unsure of basic concepts of a discipline, penetrate its complexities, let alone arbitrate disputes between its high priests? Reliance on the demeanor of experts or on their credentials is cognitively suspect, and comes close to leaving the outcome of difficult cases to chance. 96

It is the undoing of this complex knot of problems that requires us to examine the possibility of giving the non-expert decision-makers criteria to make a rational decision when faced with conflicting experts.

I will argue that, despite the effort of many, there is no single criteria (or set of criterion) which will render decisions by non-experts in the face of conflicting scientific experts as rationally justified in all situations. The alternative view here defended is to recognize that the idea of testimonial reliability operates differently within different kinds of testimony-and differently within the same kind of testimony at different times.

\subsection{Jones's loyalists versus dissidents clash}

In a 2002 paper, ${ }^{97}$ Ward E. Jones presents and puts to work a solution to the novice/2-epxert problem. Jones frames the problem as a conflict between a 'loyalist', who supports the dominant position in the scientific community, and a 'dissident' who, although a member of that community, disagrees with the dominant position in some salient aspect. ${ }^{98}$

Jones addresses the question of whether the observation that a given theory or scientific claim is accepted by the majority of a given community gives us more reason to believe in it than in a rival theory or claim only accepted, by relevant similar methods, by a minority within the same community. ${ }^{99}$ Jones affirms that to answer this question negatively would be to claim that there is 'no epistemic difference' between the two positions.

However, according to Jones, there 'is' a relevant epistemic difference between the loyalist and the dissident. He claims that a non-expert having to make a decision on the basis of

'on the basis of an epistemically substantive judgment about the merits of an expert's proffered testimony'. (Brewer, supra n 1 , p. 1617). This shows the importance of assessing whether there are criteria that could render the jury's decision justified.

${ }^{96}$ Mirjan Damaska, Epistemology and the legal regulation of proof, 2 LAW, PROBABILITY AND RISK, 2003 , at 128.

${ }^{97}$ Ward E. Jones, Dissident versus Loyalists: which scientist should be trusted?, 36 THE JOURNAL OF VALUE INQUIRY, pp. 511-520, 2002.

${ }^{98}$ I have chosen to focus on Jones's proposal in this subsection, despite its non-trivial position in the literature, for the following reason. I believe that such a proposal is quite common among legal scholars. For instance, see Schuartz, supra $n$ 4. and Adrian Vermeule, The Parliament of the Experts, 58 DUKE LAW JOURNAL 2231, 2009. In fact, this is analogous to the solution reached by the D.C. Court of Appeals in 1923, when it established the famous Frye test (Frye v. United States, 293 F. 1013 (D.C. Cir. 1923)). Concisely, the idea behind the Frye test was that courts should admit to trial only scientific expert evidence whose reliability had general acceptance within the relevant scientific community.

${ }^{99}$ Jones,supra n 97 , p. 513 and Schuartz, Ibid. 
conflicting scientific testimonies would be 'more justified' in settling with the loyalist than with the dissident. $^{100}$

Jones's 'pro-loyalist' argument may be rationally reconstructed as follows: ${ }^{101}$

' $\mathrm{J} 1$. All things being equal, one should trust testimony that is more likely to be reliable.

J2. All things being equal, the testimony of those less likely to be biased about the subject testified to is more likely to be reliable.

J3. A doxastic commitment is unbiased if (i) it is determined by what the believer takes to be epistemic considerations and (ii) it is affected by counterevidence.

J4. A scientific community's commitment to a theory satisfies (3i).

J5. A scientific community's commitment to a theory also satisfies (3ii).

J6. Given $\mathrm{J} 4$ and J5, a doxastic commitment supported by the scientific community is less likely to be biased.

J7. Given $\mathbf{J} 2$, a doxastic commitment supported by the scientific community is more reliable.

Therefore,

J8. One should trust testimony that is supported by the scientific community.'

As Jones himself puts it ' $[\mathrm{t}]$ he lesson to be drawn is that when looking to science as an authority, we have at least one reason to listen to the members of the community who are loyal to the party line, and not to those who dissent from it'. ${ }^{102}$

In short, Jones contends that the community support of one position (loyalist) over the other (dissident) yields the conclusion that the non-expert would have reason to infer that the former is less likely to be biased, thus, more likely to be reliable. Given this, the non-expert trying to assess conflicting experts should go with the loyalist. He should settle with the majority.

One major problem in Jones's argument, although by no means the only, is in both J4 and J5, namely, his sweeping proposition that both criteria of $\mathrm{J} 3$ are satisfied by the support of the relevant scientific community. ${ }^{103}$

It is worth quoting, at some length, his defense of J4:

'[P] ublication and public consideration of the claim at hand will be solely concerned with evidence for the claim. In no theoretical discourse will the public defense of a claim be non-epistemic. Scientists do not defend their theories by pointing out that they are, say, good for society or easy to teach. Therefore insofar as communal acceptance of a claim is dependent upon publication and defense of the claim, communal acceptance will be the result of consideration of epistemic support for it. 104

The implicit reasoning here is that, in order to gain support of the majority of the relevant community (and then become the 'dominant position'), any given theory or scientific claim will necessarily be subject to public scrutiny in a way that satisfies J3(i). In contrast, since a theory or claim with minority

\footnotetext{
100 Jones is careful to state that this is not to say that dissidents do not have their value for the advance of scientific knowledge and may even be right.

${ }^{101}$ For this, I draw partially on the analysis made by Almassi.

102 Jones, supra n 97, p. 520.

${ }^{103}$ Almassi, supra n 29, p. 117.

104 Jones, supra n 97, pp. 518-519.
} 
support, by definition, does not enjoy broad communal acceptance, one should be sceptical about the theory or claim having been subject to public scrutiny in a way that satisfies J3(i).

One problem with this argument is that it is certainly 'not' the case that public defence of a scientific claim 'never' resorts to, or relies on, non-epistemic considerations. One should also not put such trust in publication as the ultimate certification of approval for a claim by the scientific community. The across-the-board generalization that the support of any given claim is fully determined by publication records does not correspond with 'actual' scientific practice.

Here, insights from science and technology studies and the history of science might be helpful. Through the studies of practices in laboratories, ${ }^{105}$ governmental institutions, ${ }^{106}$ and so on, science and technology studies scholars have traced how internal dynamics are crucial for the acceptance, stability and dissemination of scientific claims. Likewise, attention is paid to which instruments are employed in each of these steps. ${ }^{107}$ Briefly, we need to pay particular attention to the fact that scientists are members of communities, working within particular sets of norms and vernaculars, created and maintained by historically and socially contingent interactions. In this sense, we begin to recognize that scientific claims are submitted for validation, persuasion and proof, through continual (informal, often invisible) negotiations among actors only partially insulated from the myriad of economic, social, political, institutional, cultural and rhetorical influences. ${ }^{108}$

Let us turn to J5, which states that the majority's position is affected by counterevidence. A community's acceptance of a claim, Jones asserts, 'is dependent on there not being any counterclaims made within the community [and] dependent on publicly asserting, and waiting for public acceptance of a claim'. ${ }^{109}$

This conclusion is taken for granted without sound support. As we are told by work in science and technology studies and the history of science, many scientific theories or claims are accepted (i.e. not

105 This work has been undertaken mainly by French sociologist, Bruno Latour, see Bruno Latour and Steve Woolgar, Laboratory Life: The Social Constructions of Scientific Facts, 1979. BRUNO LATOUR, SCIENCE IN ACTION, 1987. For a rash critique of Latour's work, see David Bloor, Anti-Latour 30 STUDIES IN THE HISTORY AND PHILOSOPHY OF SCIENCE, 1999, pp. 81-112. For work done on laboratories by other scholars see Adi Ophira and Steven Shapin, The Place of Knowledge A Methodological Survey, 4 SCIENCE IN CONTEXT, pp. 3-22, 1991.

106 SHEILA JASANOFF, THE FIFTH BRANCH: SCIENTIFIC ADVISORS AS POLICYMAKERS, 1990.

${ }^{107}$ Works on the history of science also give cases for better understanding the historically sinuated establishment of the social structure that science has. Probably the most famous example of such work is Shapin and Schaffer's book LEVIATHAN AND THE AIR PUMP: HOBBES, BOYLE, AND THE EXPERIMENTAL LIFE, 1985. See also STEVEN SHAPIN, A SOCIAL HISTORY OF TRUTH, 1994. Another canon on the literature of the mutual embedding of natural knowledge and social order is YARON EZRAHI, IN DESCENT OF ICARUS: SCIENCE AND THE TRANSFORMATION OF CONTEMPORARY DEMOCRACY, 1990, which discusses the ideological ties between modern conceptions of science and liberal democracy; and Ian Hacking's provocative reconstruction of the roots of multiple personality disorder in the USA, IAN HACKING, REWRITING THE SOUL: MULTIPLE PERSONALITY AND THE SCIENCES OF MEMORY, 1995.

${ }^{108}$ Sheila Jasanoff, Law's Knowledge: Science for Justice in Legal Settings, America Journal OF Public Health, 95, p. S53, 2005. This is not to say that claims about the social construction of knowledge leave no role for the material world to play in the making of knowledge about it. The idea is subtler. Work has to done to explore the ways in which the material world (or 'nature') is used be in the production of knowledge. Moreover, this idea does not imply to state simplistically that scientific knowledge is reducible to social factors. Critics were fast in associating those types of claims with naïve relativism (See, e.g. Ronald J. Allen and Brian Leiter, Naturalized Epistemology and the Law of Evidence, 87 Va. L. Rev. 1491 (2001), dismissing 'the unfortunate fascination in some quarters of the legal academy with "postmodern" conceptions of knowledge and truth, conceptions notable for their superficiality and for the fact that almost no philosophers subscribe to them'). But we need to be careful here, for there are just too many accounts of what relativism is in order to support such sweeping categorizations. Mainly I believe we can fairly attribute the propositions here presented as supporting relativism in the sense that they deny that there is a single set of standards entitled to govern the justifications of beliefs. Briefly, the idea would be that science has no special authority that extends beyond its local inside norms and conceptual systems.

109 Jones, supra n 97, p. 519. 
disputed) by a given community for several different reasons other than the absence of counterevidence. We can find episodes in the history of science in which claims were put forth, eventually stabilized and disseminated with the coexistence of unmatched counterevidence. ${ }^{110}$ These investigations help us to adopt a sceptical position towards Jones's assumption that the community's acceptance of a claim is solely dependent on the absence of counterevidence.

In summary, Jones relies on the idea that one way to compare the reliability of conflicting testimonies is to compare how individuals come to form their beliefs, which, in turn, can be assessed by checking for the 'absence of bias'. If we can show that one person is less likely to be biased than her rival, then, everything else being equal, we have more reason to trust the former than the latter. This is because the verification of bias entails the conclusion that the belief under scrutiny is held by 'nonepistemic explanations', i.e. explanations not related to the truthiness of the belief. 'While the dominant community may not be right, we have reason to think that Loyalists are not being moved by bias, and that may be the best that we, and policymakers, can do.'111

But is this really the 'best' we can do? I have tried to emphasize how Jones's proposed solution is committed to a naive account of scientific practice. This can be seen, for instance, in his defense that ' $[w]$ hile a political dissident is up against individuals who hold positions of power, such a hierarchy of power does not characterize science'. ${ }^{112}$

This is not to mention the foreseeable problems of operationalizing this proposition, since it leaves open important questions like, how much agreement is enough for one to be considered a 'loyalist'; what the relevant 'kind' of agreement; and how do we properly define the group within which we are searching for 'agreement' to be present. ${ }^{113}$ When trying to answer these open questions, we realize that, at the end of the day, loyalism is too blunt of a standard to serve as a general solution to every case.

\subsection{Alvin Goldman's indirect indicators}

In a 2001 paper $^{14}$, Alvin Goldman addresses the novice/2-expert problem. He begins by recognizing that our evidence about the reliability or unreliability of our source can enhance or weaken our justification in accepting testimony from that source. For instance, when we hear that there is a high probability that it will rain tomorrow, our assigned reliability to that proposition is enhanced if we discover it was uttered by a meteorologist, whereas it would be weakened if we discover it was said by a five-year-old. Goldman argues that this reasoning holds for non-experts facing conflicting expert testimonies. That is, the decision of the non-expert of which expert to settle with can be massively influenced by the empirical discoveries about each expert and their respective reliabilities. Nevertheless, given the fact that the non-expert cannot appeal to his own justificational resources (for reasons already explored), what are the kinds of empirical evidence that he might have access to for bolstering his confidence in one expert over the other?

${ }^{110}$ Shapin, supra $\mathrm{n} 16$.

111 Jones, supra $\mathrm{n} 97$, p. 520.

112 Ibid p. 518.

${ }^{113}$ An analogy here is useful. This proposition resembles the Frye-rule, a 1923 U.S. Supreme Court precedent (Frye v. United States, 293 F. 1013 (D.C. Cir. 1923)), overruled in 1993, which held that while deciding on the admissibility of any given expert evidence the judge should defer to the general acceptance of the scientific community. However, the precedent also left open the important question mentioned in the text. Thus, courts diverged in the degree of agreement they considered necessary to deem the criterion of general acceptance fulfilled. See SHEILA JASANOFF, SCIENCE AT THE BAR: LAW, SCIENCE AND TECHNOLOGY IN AMERICA, 1995, p. 62.

${ }^{114}$ Goldman, supra n 86, pp. 85-110. 
Goldman suggests that although the non-expert may lack the epistemic capacity to directly evaluate the reasons each expert holds for believing her conclusions, the non-expert might still have 'other reasons' for believing that one of the experts has better reasons for her conclusions than her rival. He articulates an open list of five evidential sources potentially available to non-experts so that they can try to determine which of the conflicting expert to trust.

'G1. Arguments presented by the contending experts to support their own views and critique their rival's views.

G2. Agreement from additional putative experts on one side or other of the subject in question.

G3. Appraisals by "meta-experts" of the experts' expertise (including credentials).

G4. Evidence of the experts' interests and biases vis-à-vis the question at issue.

G5. Evidence of the experts' post "track records".'

Let us consider the strengths and weakness of each of these propositions, beginning with G1.

In order for the non-experts to gain justification for believing one expert's view by means of their arguments, the non-expert must at least be able to understand the evidence cited in the experts' arguments. However, many times non-experts are provided only with experts' conflicting conclusions or with partial outlines of the arguments offered supporting the conclusions. Furthermore, even when arguments are provided in full detail, much of their content will be out of reach for the non-expert, by definition.

At this stage, Goldman introduces an important dichotomy between 'esoteric' and 'exoteric' statements within an expert's discourse. ${ }^{115}$ These are statements belonging to the relevant sphere of expertise or not, respectively. The main difference between them is their accessibility to non-experts. Only the truth-conditions of 'exoteric' statements are accessible to non-expert's analysis, whereas those of esoteric statements are not. Moreover, not only are non-experts usually not able to assess esoteric propositions, but they also are in a bad position to assess which expert has the strongest 'relation' between the evidence and the conclusions offered making use of esoteric propositions.

Goldman does not see G1 as completely inoperable, however, because non-experts also may acquire 'indirect argumentative justifications'.

Before fully explaining what Goldman means with 'indirect argumentative justifications', it is important to introduce another important distinction he makes, that of 'direct' and 'indirect' justification. According to Goldman, in a 'direct' argumentative justification, we 'become justified in believing the conclusion of the argument by becoming justified in directly believing the premises of the argument and its (strong) relation to its conclusion'. ${ }^{16}$ On the other hand, in an 'indirect' justification, the non-expert makes an inference from the performances of the two speakers about their respective levels of expertise in the relevant domain. Then, the non-expert makes a further inference from greater expertise to a higher probability of endorsing a true conclusion. ${ }^{17}$

\footnotetext{
${ }^{115}$ Ibid p. 94. It might also be important to mention a further distinction Goldman makes in a footnote (fn. 10), between semantically esoteric and epistemically esoteric statements. While the former is one statement, which the non-expert cannot assess because he fails to understand the grammatical construction of it (e.g. the statement might use technical terms), the latter are statements the non-expert understands the language, but still cannot assess its truth-conditions.

116 Goldman, Ibid p. 94.

117 Goldman affirms that indirect argumentative justification 'necessarily involves an inference to the best explanation' (Goldman, Ibid p. 96).
} 
If we go back to the non-expert's position, we can see how it will be difficult for him to hold direct justification of an expert's argument, given that many of the experts will probably make frequent use of esoteric arguments. But the non-expert is not without hope, for it is still possible for him to assess indirect justifications.

3.3.1 Dialectical superiority. One of Goldman's indirect justifications is what he calls an expert's 'dialectical superiority'. The idea is that the argumentative performance of an expert might be a plausible indicator of her (relatively) greater expertise, even if it does not provide the non-expert direct justification for believing the dialectically superior expert's conclusion.

It is important to notice, however, that by 'dialectical superiority', Goldman does 'not' mean merely greater debating rhetoric skills. ${ }^{118}$ But if not for rhetoric skills, what sort of dialectical superiority does Goldman have in mind as an indirect indicator of expert reliability?

Goldman mentions, for example, the fact that one expert presents an ostensible rebuttal or defeater for the evidence presented by the conflicting expert. In dialectical terms, the expert who presented such evidence would seem to be doing better in the dispute. Goldman suggests that this dialectical superiority may reasonably be taken as an 'indirect' indicator of the expert having superior expertise. ${ }^{119}$ For instance, the comparative quickness and smoothness with which one expert responds to the other expert's evidence could suggest that the former is already well familiar with the latter's argument and has already thought out counterarguments.

Of course, ostensive evidence, quickness and smoothness are problematic indicators of expertise. Skilled debaters and well-coached witnesses can appear better informed because of their debating skills, which is not a true indicator of superior expertise. So, 'why' is it the case that the indirect indicators of dialectical superiority to which Goldman alludes should enhance an expert's reliability to testify to the relevant factual question whether $\mathrm{p}$, where the question is within the boundaries of the relevant domain of expertise?

Goldman's explanation is that the expert's dialectical performance would be directly proportional to his degree of expertise in the relevant domain, hence, enhancing the reliability of his testimony on the particular question at hand. Therefore, the better the expert's performance, the better the non-expert's indirect justifications are for attributing higher trustworthiness to that expert's testimony (all things equal).

Before outlining the argument, it is worthwhile to explain one more distinction Goldman makes, this time between 'primary' and 'secondary' questions in a given domain of expertise. Primary questions are 'the principal questions of interest to the researchers or students of the subject-matter'. ${ }^{20}$ Secondary questions involve 'the existing evidence or arguments that bear on the primary questions, and the assessments of the evidence made by prominent researchers' ${ }^{121}$

With this distinction in mind, the argument goes as follows. Marks of dialectical superiority such as (a) ostensive rebuttals, (b) quicker, and (c) smoother responses to counter-evidence, according to Goldman, count as indirect indicators that the expert knows enough answers to 'secondary' questions $^{122}$ in the relevant domain of expertise to make him a more reliable expert concerning 'primary'

\footnotetext{
118 This point will be of further importance when get to Brewer's treatment of demeanour. See text bellow.

${ }^{119}$ We can see here how this is consistent with both Goldman's and Brewer's vision of expertise, which involve having control of the data and methods (and aims, in Brewer's account) of the relevant domain of expertise. See text above.

${ }^{120}$ Goldman, supra n 86 p. 92.

${ }^{121}$ Ibid p. 92.
} 
questions in the domain. Thus, his testimony about the question under consideration can be considered more reliable than that of his rival.

The reasoning underlying these associations depends on four links. ${ }^{123}$ Firstly, a link between dialectical superiority and better knowledge of the set of relevant evidence: if one expert presents a clearly dialectical superiority in respect to a rival expert, then, all things equal, the non-expert would have good reason to believe that expert (probably) knows more than the conflicting expert about the set of evidence relevant to the factual question being asked.

Secondly, a link between better knowledge of a set of relevant evidence with better secondary knowledge: if the non-expert has good reason to believe that one expert (probably) knows more than the second about the set of relevant evidence, then, all things equal, the non-expert would have good reason to believe that the first expert has better knowledge about secondary questions in the relevant domain of expertise.

Thirdly, a link between better secondary knowledge and better primary knowledge: if the nonexpert has good reason to believe that one expert has better knowledge about secondary questions, then, all things equal, the non-expert would have good reason to believe that the first expert has better knowledge about primary questions in the relevant domain of expertise.

Finally, the link between better primary knowledge in the relevant domain of expertise and greater credibility: if the non-expert has good reason to believe that one expert is in a better position than his rival to answer correctly primary questions in the relevant domain, then, all things equal, the nonexpert would have good reason to attribute greater reliability to that expert's testimony on the question under consideration (at least where that question is a primary question in that domain of expertise).

In a 2005 paper, ${ }^{124}$ David Matheson builds on Goldman to argue that such marks of dialectical superiority (ostensive rebuttal, quickness and smoothness) constitute but one class of greater reliability. He then advocates for other classes.

The first idea Matheson adds is that 'greater receptivity' to new relevant evidence indicates greater credibility. By greater receptivity he means greater disposition to consider putative relevant evidence that one has not considered until then 'even if that apparent merit threatens to call into question one's previous opinion on the question of whether p'. ${ }^{125}$ Secondly, that 'greater sensitivity to misleading evidence' indicates greater credibility. For Matheson, to be more sensitive to misleading evidence is to have a greater disposition to reconsider the merits of what one has thought to constitute relevant evidence. Thirdly, 'greater ability to manage relevant evidence'. This is related to the ability to associate distinct pieces of evidence, or, alternatively, to see how the pieces of evidence 'fit together into one coherent whole, relevant to the question at hand'. ${ }^{126}$

Matheson's reasoning in defence of his additional criteria requires similar links to those constructed above to support Goldman's ideas, with one extra step. In addition to the link between better secondary knowledge and primary knowledge (third link), we will need a link between greater managerial ability

\footnotetext{
122 The distinction Goldman makes between primary and secondary questions is crucial here. 'Primary questions are the principal questions of interest to the researchers or students of the subject-matter. Secondary questions concern the existing evidence or arguments that bear on the primary questions, and the assessments of the evidence made by prominent researchers.' (Goldman, Ibid p. 92).

${ }^{123}$ This analysis in partially a reflection on David Matheson, Conflicting Experts and Dialectical Performance: Adjudication Heuristics for the Layperson, 19 ARGUMENTATION, 2005, pp. 145-158.

${ }^{124} \mathrm{Ibid}$.

125 lbid p. 152.

${ }^{126}$ Ibid p. 154.
} 
(likewise to sensitivity and receptivity) and better secondary knowledge, so that: if the non-expert has good reason to believe that one expert is better able to manage evidence (or has higher sensitivity, or higher receptivity), then, all things equal, the non-expert would have good reason to believe that the first expert has better secondary knowledge in the relevant domain (then he is in a better position to assert answers to primary questions in that domain, and thus, can be considered more reliable). ${ }^{127}$ Thus, to the extent that these indicators can be differentiated from mere rhetorical skills, there might be a possible workable solution to the novice/2-expert problem in some cases. The easiness and trustworthiness of their assessment, however, is more difficult to grasp.

Let's now turn to Goldman's other criteria. We will get back to some of the ideas explored in this subsection further below when we deal with Brewer's scepticism.

3.3.2 Going by the numbers. The additional strategy for the non-expert offered by Goldman is to appeal to other experts, which leads us to G2 and G3. According to this solution, the non-expert should consult the expert who has support from the higher numbers of other experts. Goldman asks: 'Should not the non-expert be justified in trusting one expert over the other, if almost all other (or even a preponderance of the) experts in the field agree with him/her?' (G2). ${ }^{128}$ Or, should not the non-expert consult third parties' ('meta-experts') assessments of each conflicting expertise? (G3). ${ }^{129}$ In any case, if an expert's testimony is supported by the consensual opinion of other experts, how much warrant does that give the non-expert to assign higher credibility to the first expert? As we shall see, the answer to this question is anything but simple.

Wittgenstein famously joked about the futility of a man who buys several copies of his morning newspaper to get more support for its claims. ${ }^{130}$ In considering the epistemic significance of concurring opinion, Goldman worries that a strategy of 'going by the numbers' might be no better than Wittgenstein's newspaper anecdote.

If we blindly follow the insights discussed above about considering testimony as evidence for the claim being testified, despite the absence of evidence of the expert's reliability on the domain of expertise relevant to the question under consideration, then counting heads of people supporting the expert's proposition would seem to be very promising. As we gather more testimonies in support of a given proposition, more weight attribute to it.

Goldman provides an example in an attempt to expose serious doubt about the evidential meaningfulness of the 'going by the numbers' strategy. ${ }^{131}$ Goldman describes a guru and his many slavish followers who uncritically believe and testify to whatever he believes or says. If we have reason to believe that these slavish followers are mere receptors of the guru's beliefs, paying blind allegiance to him, then, Goldman correctly argues, it seems that the number of followers that support the guru's proposition should not weight positively to his side.

\footnotetext{
${ }^{127}$ However, we should be aware of situations in which we are dealing with inter-disciplinary conflicting experts (or as Brewer calls this situations: 'extra-disciplinary conflicts', Brewer, supra n 1, 1632).

${ }^{128}$ This proposal looks a bit like Jones's pro-loyalist solution discussed previously, however, it is still helpful and interesting to discuss it here, for Goldman takes a drastically different approach and provides a different justification than Jones does.

${ }^{129}$ Credentials can be viewed as a special case of this same process. Academic degrees, professional accreditations, work experience, and so forth (all from specific institutions with distinct reputations) reflect certifications by other experts of both experts' demonstrated training or competence. The relative strengths or weights of these indicators might be utilized by the non-expert to distil appropriate levels of trust for both experts. But see Brewer's position on this issue in the text below.

${ }^{130}$ Wittgenstein, supra $n 39$, p. 265.

131 Goldman, supra $n 86$, p. 98.
} 
So it is definitely 'not' the case that, in every scenario, the number of supporters should add to the credibility of a proposition. Goldman anticipates the objection that in the conflicting scientific experts case (our main concern here), as opposed to the guru example, the non-expert might have some reason to think that each new speaker who concurs with one of the originals has some credibility and is not an 'uncritical slavish follower'. Thus, one could ask whether in the conflicting scientific experts case, 'going by the numbers' is a winning strategy.

Some authors answer that question in the affirmative. In the model developed by Lehrer and Wagner in $1981,{ }^{132}$ for instance, each new supporter provides an additional 'vector' that pushes the subject in the direction of the supported expert's testimony.

To highlight the problem with this approach, Goldman offers the 'non-independence principle', formulated in the following way:

'[i]f two or more opinion-holders are totally nonindependent of one another, and if the subject knows or is justified in believing this, then the subject's opinion should not be swayed - even a little - by more than one of these opinion- holders. ${ }^{133}$

In the guru example, it is clear that the slavish followers fail to pass the independence test. But what about experts?

Goldman's reasoning is elaborated through a Bayesian analysis. We are asked to conceive a situation in which experts $\mathrm{X}$ and $\mathrm{Y}$ give testimonies to the truth of hypothesis $\mathrm{H}$. The question is posed to the non-expert $\mathrm{N}$. When does $\mathrm{Y}$ 's testimony for $\mathrm{H}$ add to the evidence provided by $\mathrm{X}$ 's testimony for $\mathrm{H}$ ? To properly assess this question, we should focus on the ratio of two likelihoods: the likelihood of $Y$ giving a testimony supporting $\mathrm{X}$ 's if $\mathrm{H}$ is 'true' and the likelihood of Y giving a testimony supporting $\mathrm{X}$ 's if $\mathrm{H}$ is 'false'.

For example, this ratio for $\mathrm{X}$ can be formulated as follows:

$$
(\mathrm{P}(\mathrm{X}(\mathrm{H}) \mid \mathrm{H})) /(\mathrm{P}(\mathrm{X}(\mathrm{H}) \mid \sim \mathrm{H}))
$$

where $\mathrm{X}(\mathrm{H})$ stands for $\mathrm{X}$ believing $\mathrm{H}$ and $\mathrm{Y}(\mathrm{H})$ for $\mathrm{Y}$ believing $\mathrm{H}$. Now, compare (1) with:

$$
(\mathrm{P}(\mathrm{X}(\mathrm{H}) \& \mathrm{Y}(\mathrm{H}) \mid \mathrm{H})) /(\mathrm{P}(\mathrm{X}(\mathrm{H}) \& \mathrm{Y}(\mathrm{H}) \mid \sim \mathrm{H}))
$$

If it is really the case that Y's testimony supporting $X$ 's position is evidentially meaningful, then, Goldman argues, (2) > (1). That is to say that if $Y$ also supports $H$, then it should be the case the likelihood of $\mathrm{H}$ being 'true' should 'increase' with Y's support. Otherwise (i.e. if Y's support does not render $\mathrm{H}$ a higher probability of being truth), the non-expert would not be justified in assigning a higher reliability to $\mathrm{X}$ in light of $\mathrm{Y}$ 's testimony supporting $\mathrm{X}$.

Such comparative analysis is in order when the non-expert has good reason to believe that each of the experts (X or $\mathrm{Y}$ ) is 'reliable' and 'independent'. Goldman expands his argument to try to show that such conditions do not always hold.

\footnotetext{
${ }^{132}$ KEITH LEHRER AND CARL WAGNER, RATIONAL CONSENSUS IN SCIENCE AND SOCIETY, 1981. Lehrer and Wagner say (p. 20) that one should assign somebody else a positive weight if one does not regard his opinion as 'worthless' on the topic in question-i.e. if one regards him as better than a random device. So it looks as if every clone of a leader should be given positive weight-arguably, the same weight as the leader himself, since their beliefs always coincide-as long as the leader receives positive weight. In the Lehrer-Wagner model, then, each clone will exert a positive force over one's own revisions of opinion just as a leader's opinion will exert such force; and the more clones there are, the more force in the direction of their collective opinion will be exerted.

${ }^{133}$ Goldman, supra n 86, p. 99.
} 
As an illustration, let us go back to the guru and slavish followers example. If $Y$ is one of the guru's blind followers then, whatever $\mathrm{X}$ (the guru) testifies to, $\mathrm{Y}$ will promptly agree, regardless of whether $\mathrm{H}$ is actually true or false. The comparative analyses in this example would look something like this:

$$
\mathrm{P}(\mathrm{Y}(\mathrm{H}) \mid \mathrm{X}(\mathrm{H}) \& \mathrm{H})=\mathrm{P}(\mathrm{Y}(\mathrm{H}) \mid \mathrm{X}(\mathrm{H}) \& \sim \mathrm{H})=1
$$

Thus, in the guru scenario, (2) is the same as (1), making 'unwarranted' any kind of revision on X's reliability on Y's supportive testimony.

Let us change scenarios. Consider that another testifier $\mathrm{Y}$ is now 'not' a blind follower of $\mathrm{X}$. $\mathrm{Y}$ now might agree with $\mathrm{X}$ in some instances, while disagreeing with him in others. Does this mean that Y's supportive testimony always provides the non-expert epistemic justification to assign $X$ 's testimony higher reliability? Goldman answers negatively.

The relevant question to be posed is whether $\mathrm{Y}$ is more likely to believe $\mathrm{H}$ (and so, agree with $\mathrm{X}$ ) when $\mathrm{H}$ is true, than when $\mathrm{H}$ is false. If $\mathrm{Y}$ is as likely to believe $\mathrm{H}$ (that is, to agree with $\mathrm{X}$ ) independently of $\mathrm{H}$ being true or false, then, his testimony should 'not' count positively to the non-expert belief towards H nor X's reliability. This latter hypothetical scenario can be represented in the following way.

$$
\mathrm{P}(\mathrm{Y}(\mathrm{H}) \mid \mathrm{X}(\mathrm{H}) \& \mathrm{H})=\mathrm{P}(\mathrm{Y}(\mathrm{H}) \mid \mathrm{X}(\mathrm{H}) \& \sim \mathrm{H})
$$

If (4) holds, then, again, (2) is reducible to (1), and so, the non-expert gets no further support from Y's agreeing with $X$. As long as $Y$ is as likely to follow $X$ when $H$ is true as when $H$ is false, we will get this result. Thus, $\mathrm{Y}$ 's testimony for $\mathrm{H}$ supporting $\mathrm{X}$ is only 'evidentially meaningful' when $\mathrm{Y}$ 's belief in $\mathrm{H}$ is at least 'partly conditionally independent' of $\mathrm{X}$ 's belief in $\mathrm{H}$. This is the case when the following holds:

$$
\mathrm{P}(\mathrm{Y}(\mathrm{H}) \mid \mathrm{X}(\mathrm{H}) \& \mathrm{H})>\mathrm{P}(\mathrm{Y}(\mathrm{H}) \mid \mathrm{X}(\mathrm{H}) \& \sim \mathrm{H})
$$

According to Goldman, 'fully conditional independence is a situation in which any dependency between $\mathrm{X}$ and Y's beliefs is accounted for by the dependency of each upon $\mathrm{H}$ '. ${ }^{134}$ And although we should not demand full conditional independence in order to allow the non-expert to make a warranted revision to X's reliability on Y's supportive testimony, we should demand 'partial conditional independence'. ${ }^{135}$

The greater the conditional independence of $Y$ from $X$ (by the non-expert's eyes), the more epistemic significance can be attached to $Y$ 's agreeing with $X$ about $H$. This way, the independence convergence of experts towards $\mathrm{H}$ is more epistemically significant than the echoes of uncritical slavish followers of one single source.

The trouble with these strategies is that a non-expert cannot automatically count on his experts being even partially conditionally independent of one another. ${ }^{136}$ And if any additional expert is not partially conditionally independent of the original expert whose reliability the non-expert is trying to assess, then, they should not add further weight to original expert position.

What kind of evidence (if any at all) can the non-expert have to justify his acceptance of (5)? Goldman points to cases where $\mathrm{Y}$ has followed an inquiry to form his belief in $\mathrm{H}$ that, even in situations where $\mathrm{H}$ was false, but $\mathrm{X}$ testified for its truthiness, $\mathrm{Y}$ would still recognize its falsehood.

\footnotetext{
134 Ibid p. 101.

135 Ibid p. 101.

${ }^{136}$ Ibid p. 101-102.
} 
Goldman gives two possible scenarios for this. ${ }^{137}$ One is when Y's path of inquiry 'bypasses' X's. By this, Goldman means that each expert holds independent paths of inquiry. For instance, when $X$ and $\mathrm{Y}$ are independent eyewitnesses, or when both base their beliefs on independent experiments concerning $\mathrm{H}$. The second scenario is one in which $Y$ 's path of inquiry goes 'partly through' $\mathrm{X}$ 's, but does not involve uncritical reflection of $X$ 's beliefs. This includes examples in which $Y$ might consider (partially) X's belief, but goes on to consider a set of possible rebuttals for it and ends up falsifying it. ${ }^{138}$

Goldman asserts that, in some situations, the non-expert might be justified to presume a partial independence among the experts in consideration. He mentions scientists as an example where such a presumption might be warranted, since a non-expert might 'have reason to expect [scientists] to be critical of one another's viewpoints'. Interestingly, Goldman recognizes that insights from sociology of science (he explicitly mentions the works of Latour and Woolgar) might undermine this presumption. He affirms that if we take these 'extreme views' seriously, then no one would ever be entitled to believing anything like (5).

But that does not need to be the case. Even though unsupported radical statements might have been made in the past by particular authors, reducing the insights of science and technology studies to a 'merely social constructive' view, where all knowledge generated never reflects the real world, but only the opinions, interests and so forth of a given community, is a stretch of an impoverished reading of the literature.

A more nuanced and up-to-date take on science and technology studies literature might give us interesting insights, without committing us to such extreme propositions as Goldman (unfairly, in my view) attributes to Latour and Woolgar. Although portrayed differently by its critics, science and technology studies involves a project of social theorizing that goes far beyond relativism. In the end, we are not left to choose between sceptical relativism or naïve idealization. Between the Scylla of strong social constructivism, and the Charybdis of idealized visions, we can choose a middle ground position, which does not mean only 'splitting the differences' but that fully acknowledges the social factors involved in the production and stabilization of scientific claims, and yet recognizes that one actual and reasonable aim of science it gives us an accurate description of what reality is like. ${ }^{139}$

In any case at the end of his analysis, Goldman still shows scepticism with the 'going by the numbers' strategy. Mainly, as the discussion above showed, the basic criteria upon which the nonexpert needs to depend are both how 'reliable' and 'conditionally independent' the experts under consideration are. Thus, if it is the case that the minority of the relevant community are perceived as more reliable and more 'conditionally independent' than the members of the majority, that might

\footnotetext{
${ }^{137}$ Ibid p. 102.

${ }^{138}$ Almassi seems to fail to recognize this (although he clearly mentions it). See Almassi, supra n 29, p. 136.

${ }^{139}$ E.g. Latour argues that 'scientific facts are indeed constructed, but they cannot be reduced to the social dimension'. BRUNO LATOUR, WE HAVE NEVER BEEN MODERN, 1993, p. 6. See also, Slavoj Zizek, Lacan between cultural studies and cognitivism, in LACAN AND SCIENCE (eds. J. Glynos \& Y. Stavrakis, 2002), p. 299: '[I]s historicist relativism [. . .] really the only alternative to naive realism [. . . ?'' Zizek argues that the answer to this false dichotomy was already indicated in Thomas Kuhn's work when 'he claimed that the shift in a scientific paradigm is more than a mere shift in our (external) perception on' perception of reality, but nonetheless LESS than our effectively "creating" another new reality'. In this sense, I disagree with Peter Huber, when he affirms that '[s]ome will always insist that all truth is relative and subjective, that anyone should therefore be allowed to testify to anything, that science must be viewed as a chaotic heap of unconnected and contradictory assertions, and that the best we can do is invite the jury to decide scientific truth by majority vote. But anyone who believes in the possibility of neutral law, as many fortunately still do, must at the same time believe in the existence of objective fact, which ultimately means positive science. The only real alternative is nihilism'. (Peter Huber, Junk Science in the Courtroom, FORBES, 8 July 1991, p. 72).
} 
imply that the minority weights more than the majority. The rule-of-thumb of going with the majority prescribed by the strategy of 'going by the numbers' simply does not work in all cases.

'Certainly the numbers do not necessarily outweight considerations of individual reliability and mutual conditional independence. The latter factors seem more probative, in the present case, than the weight of sheer numbers. 140

David Coady presents an insightful critique of Goldman's reasoning. ${ }^{141}$

Although Coady acknowledges that Goldman is ultimately right about his assertion that the 'going by the numbers' strategy is often a bad idea, Coady thinks Goldman's reasoning is wrongheaded. He asserts that Goldman negation that a follower's opinion should provide additional grounds for accepting the guru's view is 'not' in general true. According to Coady, this would only hold if we could presume that the followers are more often than not unreliable judges 'of' gurus, although not judges of their propositions. ${ }^{142} \mathrm{He}$ believes we are not justified in holding this presumption. 'The procedure of "going by the numbers" may well be the only available rational procedure for a novice who lacks the requisite time, ability, or energy to do this. ${ }^{143}$

If it is the case that the non-expert believes $\mathrm{Y}$ to be a reliable judge about whether $\mathrm{X}$ is a reliable judge of whether $H$ is true, then the non-expert's confidence in X's expertise concerning $H$ might be 'increased' by her confidence in Y's meta-expertise. This might be the case, Coady argues, even with such a scenario that does now satisfy Goldman's non-independence principle. ${ }^{144}$

3.3.3 Conflicts of interest and biases. Moving down on Goldman's list, we get to G4. Goldman defends that non-experts are justified in attributing greater reliability to experts they have reason to believe are less biased or have fewer conflicting interests (or none at all).

Goldman defends that non-experts are justified in assigning a lower reliability to an expert's testimony when faced with 'evidence of distorting interests and biases that might lie behind a putative expert's claims' ${ }^{145}$ Examples of such biases and conflicts of interest are more diverse than simple lies. For instance, repetitive testifiers (so-called 'hired-guns ${ }^{\text {, }}{ }^{146}$ ) have an economic and reputational interest in shaping their testimony in a sense that yields higher positive net expected incomes. Of even greater significance, partially because it is usually very discrete to both the expert and the non-expert, is a bias that might infect a whole discipline, such as the exclusion or underrepresentation of minorities.

Benjamin Almassi develops this point about biases further by suggesting that interests could also be recognized as 'good' sometimes, that is, as indirect indicators of 'greater' reliability. He proposes that we 'distinguish between interests which motivate an expert to do better, more reliable work and offer better, more conscientious and competent testimony, on the one hand, and interests likely to make an expert's testimony less trustworthy on the other'. ${ }^{147}$

${ }^{140}$ Goldman, supra n 86, p. 104.

${ }^{141}$ David Coady, When Experts Disagree, EPISTEME, 2006.

${ }^{142}$ Recall the difference between believing a person and believing a proposition.

${ }^{143}$ Coady, supra n 141 , p. 76.

144 The problems with the idea of meta-expertise will be further elaborated below.

${ }^{145}$ Goldman, supra n 86, p. 104.

${ }^{146}$ See, e.g. Steven D. Easton, Ammunition for the Shoot-Out with the Hired Gun's Hired Gun: A Proposal for Full Expert Disclosure, 32 ARIZONA STATE LAW JOURNAL 465 (2000); Richard A. Epstein, A New Regime for Expert Witnesses, 26 VALPARAISO UNIVERSITY LAW REVIEW 758 (1992).

${ }^{147}$ Almassi, supra n 29, pp. 124-125. 
Is it more within the expert's interests to 'win' the case or to testify truthfully? Depending on how we answer that question, we might end up with a cause for concern, or with an indirect indicator of greater reliability. On one hand, the reliability of an expert's research challenging the causation between cigarettes and lung cancer may be undercut if the non-expert has evidence that particular research was requested and funded by tobacco companies. On the other hand, the testimony of an oncologist who happens to have, or who lost a close relative due to, lung cancer after a lifetime of smoking, might have its (relative) reliability enhanced.

From a practical point of view, evidence about an expert's potential bias and interests is often more available and accessible to non-experts than other pieces of evidence. Certainly it is not unusual, especially in the courtroom, for experts to have a bias that might be said to compromise their credibility. However, it might be the case that there are non-negligible differences both available and accessible to non-experts, which could be used to assign more credibility to one expert's conclusion over the conflicting one.

One potential critique of this point is that it is by no means a clear inverse correlation between the level of bias or conflicts of interest and higher credibility of the expert's testimony. This becomes clear if we remember the distinction, as Brewer pointed out and developed above, between believing a person and believing a proposition. It can be the case that a scrupulous testifier still holds true beliefs about the subject matter that he is testifying on.

However, if we recognize that such criteria does not necessarily always yield results in one direction, but only can give the non-expert one possible justification to increase the reliability first assigned to one (or both) expert, then we might be more willing to accept it as a possible solution in some scenarios, whereas not in others. This will depend, for instance, on whether in the particular case the decision maker faces, there is good reason to believe in an inverse correlation between bias and credibility.

3.3.4 Tracing past track records. We finally get to G5. Goldman shows optimism about past records of successes and failures serving as indirect indicators that the non-expert could use to assess an expert's reliability. This means looking at the expert's 'past success rate' for the answers given by her to previous questions in her field of expertise.

But given his inferior epistemic position when compared to the expert, how can the non-expert have any justifiable belief about past answers in the expert's field by which to assess the expert's reliability? Here Goldman makes a quite clever manoeuvre. Reminding us of esoteric/exoteric distinction, Goldman defends that it is a mistake to think that statements are categorically either 'esoteric' or 'exoteric'. ${ }^{148}$ In fact, '[a] given statement is esoteric or exoteric only relative to an epistemic standpoint or position'. 149

This means that a given statement can be rendered esoteric relative to one epistemic position, while exoteric in relation to a different epistemic position. This change of epistemic position can happen, for instance, from time to time. A statement considered esoteric at some period, can be later deemed exoteric, and then be assessable to non-experts. The important insight is that, once an expert's past esoteric claim has become exoteric, non-experts could judge it in retrospect in order to construct the expert's past track record. With such information in hand, the non-expert could than be able to assess which 'esoteric' conflicting expert testimonies should be attributed a higher credibility.

\footnotetext{
${ }^{148}$ For the difference between 'esoteric' and 'exoteric' statements, see supra note 117 and accompanying text.

${ }^{149}$ Goldman, supra n 86 , p. 106.
} 
Consider the following example. An astronomer in 2011 makes a prediction that the next sun eclipse observable on earth will take place on 3 September 2020 and will be best seen in South America. Relative to our present epistemic standpoint (as non-experts in astronomy living in the year 2013), this is an 'esoteric' statement, and, by definition, as non-experts we have no means of assessing its truth conditions. However, on the day of the predicted sun eclipse, ordinary people on the street in Rio de Janeiro, Brazil, will quite easily be able to correctly answer the question whether there is a sun eclipse occurring at that moment or not. In such a different epistemic position, the astronomer's statement becomes 'exoteric'.

If we accept this contention, we can perhaps conceive that a non-expert might be able to assess that the same individual repeatedly exhibited the capacity to assert statements (esoteric at the time they were uttered, but that of late became exoteric), which turned out to be proven right under the now exoteric circumstances. Based on this reasoning, the non-expert would be then able to assign a higher reliability to the expert with the higher record of past successes.

The argument requires the same links as the arguments for dialectical superiority discussed above. If one expert presents a clearly superior past track record in respect to a rival expert, then, all things equal, the non-expert would have good reason to believe that expert (probably) knows more than the conflicting expert about the secondary and/or primary questions in the relevant domain of expertise. Hence, the non-expert would have good reason to attribute greater reliability to that expert's testimony on the question under consideration.

On this point, we need to further underline that the vast majority of (esoteric) questions answered by experts are not simply reducible to yes-or-no types of questions. ${ }^{150}$ Quite the contrary, they will consist of innumerable possible answers, sometimes indefinite numbers. Think about the eclipse example mentioned above. An astronomer in the year 2011 faces an indefinite number of possible answers to the question, 'When will the next sun eclipse occur?' Choosing from among a list of infinite possibilities, an answer that turned out to be the correct one is unlikely to be the result of a lucky guess.

Although this might be a clever attempt to dispel utter scepticism about the novice/2-expert situation, Goldman himself acknowledges that 'only occasionally will a novice know, or be able to determine, the track records of the putative experts that dispute an issue before him'. ${ }^{151}$ He further concedes that, ' $[a]$ juror in a civil trial has no opportunity to run out and obtain track record information about rival expert witnesses who testify before him'.152

As we pointed out earlier, the judge and juror do work under relatively tight constrains. However, one may argue that the adversarial system creates the incentives so that the 'parties' engage in the arduous task of tracing the past track record of the expertise on the bench. In a sense, the foreseeable difficulties are more the result of institutional design than theoretical impossibility.

Almassi criticizes this proposal by stating that if the non-expert is to have reason to appeal to an expert's past triumphs in deciding whom to trust in the present dispute, she must have reason to believe that the formerly-esoteric non-exoteric statement is 'evidentially linked" ${ }^{153}$ to that statement which remains esoteric and is currently under consideration. And the ability of the non-expert to competently assess the situation would depend in part on whether this evidential linkage is itself exoteric or esoteric, something variable from case to case.

\footnotetext{
150 Ibid p. 107.

${ }^{151}$ Ibid p. 108 . However, in other passages, Goldman expresses an optimism towards this proposal, stating that it 'may provide the novice's best source of evidence for making credible choices'. (Ibid p. 106).

152 Ibid p. 108.

${ }^{153}$ Almassi, supra n 29, p. 128.
} 
Almassi's concern is easy to grasp, but might miss the point. He is concerned with situations in which a non-expert is able to assess the past track record of an expert, but such record is not correlated to the relevant question under scrutiny. The insight underlying this critique is that if my correct answer to a given previous question is to be taken as evidence of greater reliability of answering future questions, one would have to show the existence of a link between my previous answer and my present one. For instance, if a physician made in the past a statement which later proved to be 'right' about the correlation between smoking and lung cancer, it is hard to picture why that must serve as evidence of greater reliability of the same physician's capacity to answer a present question about DNA testing.

This concern is justifiable. We certainly should not think that past answers in peculiar totally nonrelated cases enhance an expert's reliability about the current question under discussion. However, I believe that this concern misses the point.

Goldman's idea certainly is 'not' that 'any' past record should count positively towards an expert's reliability. We can see this in the following passage: 'using a past track record means looking at the candidate's past success rate for previous questions in the E-domain to which she offered answers'. ${ }^{154}$ So, only record of past statements within the relevant domain of expertise should count positively towards one's past track record for purposes of inferring present reliability.

Almassi fails to recognize this point. Underlying this reasoning is the idea that not every statement in the relevant domain of expertise needs to be esoteric. There may also be a set of exoteric statements within that domain, and 'they are the statements for which a novice might assess a candidates expertise'. ${ }^{155}$

The point is that if the non-expert is able to compare the success rate of both experts and see that the balance weights more to one side, this would give the non-expert an indirect indicator that the more historically successful expert should be more reliable. Certainly, again, this is not a guarantee that, in the current case, he will be right. The point is only that it could serve as a possible, even if fallible, indirect indicator of greater reliability, no more than that.

Thus, I believe that if properly understood, Goldman's track records proposition does not require that the non-expert be able to 'link' the previous expert's successes or failures to the now relevant factual question. Certainly, if she could do so, it would give her even 'more' epistemic justification for believing in one expert or the other. However, this should not be 'required'.

Nonetheless, Almassi does give us an interesting insight to think about this proposal. He contends that Goldman constructs it in terms that are too narrow, relating it only to assessment of the truthiness or falsehood of past claims. However, Almassi argues, this unexplained restriction limits us from considering the track record of the experts' 'skills'. ${ }^{156}$ Trying to correct for such narrowness, Almassi advocates for the extension of the original proposal to also include an expert's past success or failure in 'accomplishing expert tasks', or 'include one's ability to perform key scientific practices' ${ }^{157}$ Sometimes non-experts can know that an expert can do an expert task without knowing how that task is done. This proposition is supported by the assumption that if we have indirect evidence that a

${ }^{154}$ Goldman, supra n 86, p. 106. Again, Goldman relies on the existence of a boundary between expert knowledge and lay knowledge that is sharper than as it actually exists.

155 Ibid p. 106.

${ }^{156}$ It might be worthwhile to remember that the idea of 'expertise skill' is embedded in Goldman's (and also Brewer's) notion of expertise (which encompasses the use of data and methods in the relevant domain of expertise). See Section 2.4. above (on expertise).

${ }^{157}$ Almassi, supra n 29, p. 129. 
given expert can well perform (or better than some other) some basic tasks of a relevant domain of expertise, then the non-expert should award her a higher reliability.

I believe this alternative is ingeniously constructed and it might help in some circumstances. However, the many obstacles impeding an easy and roughly accurate estimate of past track records should make us at least cautious not to overstate its potentiality.

\subsection{Scott Brewer's possible routes and the 'Two-Hat' solution}

In a 1998 paper, ${ }^{158}$ Scott Brewer also addresses the novice/2-expert problem. He argues for three main conclusions. First, that the non-expert must understand the cognitive aims and methods of the relevant domain of expertise in order not to make an 'epistemically arbitrary' decision, in relation to which of the competing scientific experts should be assigned more reliability.

Secondly, when facing conflicting scientific experts, since non-experts lack understanding of the cognitive aims and methods of the relevant domain of expertise, they tend to rely on indirect indicators of expertise, such as credentials, reputation, and demeanor. Brewer believes this strategy only yields epistemically arbitrary judgements.

Thirdly, given this strategy, the conclusions that non-experts reach concerning conflicting scientific expert testimonies are often also epistemically arbitrary and, therefore are not 'legally' justified.

This last move is based on Brewer's identification of a norm pertaining to the set rule-of-law values: an 'intellectual due process norm'. According to Brewer, this particular norm places 'important epistemic constraints on the reasoning process by which legal decision makers apply laws to individual litigants. ${ }^{159}$

Brewer arrives at these sceptical conclusions after having analysed what he calls the four 'possible routes' by which a non-expert could make a justified decision about which of the conflicting experts to defer to. Brewer's conclusion is that none of the alteratives he develops allows the non-expert to make a justified decision, leaving us in an utterly sceptical scenario. He further argues in defence of a 'twohat solution'.

Let us discuss in some detail his propositions and analyse his two-hat solution in order to see if it is indeed a viable alternative. We will then move to consider whether we are doomed to throw in the towel on behalf of scepticism, or if there is any way we can get out of it.

My general claim is that Brewer's particular construction of the problem prepares the ground upon which he erects his scepticism (and self-declared state of aporia). However, if we construct the issue slightly different, we might be able to grasp the essential dilemmas of it, and yet not finish with flat-out scepticism. In the end, I want to argue that, despite Brewer's scepticism, we can have good reason to believe that non-expert legal decision-makers facing conflicting scientific experts' testimonies can make epistemically justified decisions regarding which expert to settle with.

3.4.1 Substantive second guessing. This proposal would entail that the non-expert, when faced with conflicting scientific expert testimonies, should try to directly assess their claims and the reasoning and/or methods supporting it. However, considering that, by definition, the non-expert is not familiarized with the aims, methods, and data of the relevant domain of expertise, the route of second-guessing the experts as a warranted strategy is easily ruled out. In this sense, although this

158 Brewer, supra n 1.
${ }^{159}$ lbid p. 1549. 
alternative seems strange to be considered at all, Brewer does so for the fact that the American legal system (and others as well) seems to require that non-expert decision-makers choose between conflicting experts 'on the basis of an epistemically substantive judgment about the merits of an expert's proffered testimony'. 160

Given that we are dealing with non-experts here, such a proposal is clearly not acceptable, as Brewer recognizes.

3.4.2 Canons of rational evidentiary support. It might be the case that some type of rational incoherence that is traceable by a non-expert afflicts an expert's decision.

Consider, for instance, the case of an expert that presents a self-contradictory testimony. It is certainly the case that flat-out self-contradiction counts against one's reliability. A further example is the failure to properly account for the important distinction between causation and non-prevention.

These two quick examples show how some canons of rational evidentiary support are easier to spot. However, others might be more difficult, and, then, might remain unnoticed. Flat-out contradiction might be easier than the sometimes-not-so-subtle distinction between a substance causing something and not preventing it. ${ }^{161}$

In any event, Brewer believes that in only a small percentage of cases will the route of canons of rational evidentiary support be promptly and easily available to non-experts. The reason for this, according to him, is that it is probably the case that failures of rationality will be more often 'hard cases' for the non-expert to discern. The more difficult it is to spot an entrenched not-so-obvious contradiction, the more knowledge in the relevant domain of expertise is required to properly notice the problem. Moreover, it is certainly the case that non-experts might misinterpret some part (usually a complicated one) of the expert testimony as self-contradictory, when that is not necessarily the case. For Brewer, this puts the non-expert in serious trouble, and makes us doubtful of the likelihood of this route yielding much result. ${ }^{162}$

3.4.3 Demeanour. When I discussed the topic of epistemic deference, I mentioned to what extent a speaker's demeanour might be important so that the hearer can evaluate the speaker's testimony. I will not resume that discussion here. In this subsection, our focus is whether demeanour is likely to, in general, provide a warranted platform that a non-expert can use in deciding between conflicting expert testimonies. $^{163}$

Brewer is critical of such possibility. ${ }^{164}$ First, he thinks we should not have any reason to believe that an expert's demeanour has any necessary connection to a higher reliability of his testimony.

${ }^{160} \mathrm{Ibid}$ p. 1617. Brewer also gives another reason to consider second-guessing. That is the idea that his construction of epistemic deference does not rule out deference by equals, so that it would involve situations in which second-guessing could be considered as a viable strategy. However, since our main concern here is with the non-expert, for space constrains I will proceed without discussing this reasoning further, without, I believe, much loss.

${ }^{161}$ Here I assume more of a position of distrust towards non-expert's capacity to easily make such distinctions than Brewer does. For instance, Brewer's example of Potter v. Eli Lilly \& Co. (926 S.W.2d 449 (Ky 1996)) illustrating this point offers support for my doubtfulness, since, according to Brewer himself, even though the deliberations of the jury were not reported, there is no indication of the extent to which the jury relied on this distinction in deciding in favour of the defendant.

162 Brewer, supra n 1, p. 1621.

${ }^{163}$ It is worth highlighting that, although closely related, Brewer's discussion on demeanour is essentially different from Goldman's discussion on dialectical superiority (presented above). Briefly, Goldman emphasizes that he is more interested in formal dialectical superiority than in apparent expert persuasiveness.

164 Brewer, supra n 1, pp. 1622-1624. 
Furthermore, for Brewer, the justification for the non-expert to take this route is further weakened due to his limited epistemic capacity to assess in a competent way the epistemic warranty of the expert's testimony independently of the features that make that expert 'seem' convincing.

Also, Brewer acknowledges that demeanour is an untrustworthy guide where there is a lucrative market for demeanour itself. ${ }^{165}$ This is of particular importance in legal settings, given the widespread practice of lawyers choosing expert testifiers on the main basis that they will 'appear' competent, in contrast to (in the lawyer's judgement) actually being competent. Brewer concludes,

'given what the market is selecting for (something that will convince jurors who are not competent to judge substantive scientific argument), there is no reason to believe that epistemic warrant has any particular connection with what chosen experts will say'. ${ }^{66}$

3.4.4 Credentials. Brewer's last foreseen route is the non-expert's resort to the experts' credentials. ${ }^{167}$ It is fair to assume that some people could consider analysing an expert's credentials as a good proxy of his reliability as an expert. Certainly, some might defend that a putative expert with a $\mathrm{PhD}$ in the relevant domain of expertise, in general, is (or should be treated as being) more reliable than one without a PhD But is this so simple?

Brewer gives us three reasons why we should be sceptical about the possibility of using credentials as an epistemically available strategy so that the non-expert can measure and compare the reliability of two conflicting scientific experts testimonies. Those reasons are regress, question begging, and underdetermination. Let us discuss each in turn.

First, the problem of regress. ${ }^{168}$ In assessing a given expert's credentials, what should the non-expert be looking for? A PhD? A master's degree? From which school? Is a $\mathrm{PhD}$ from a leading university worth more reliability than one from a less prestigious university? How to handle cases of extradisciplinary conflict?

In a scenario with widespread formal credentials, the non-expert would need assistance to distinguish those credentials he should assign a heavier weight to in the case of conflicting expert testimonies. ${ }^{169}$ The picture gets even more complicated when dealing with (as is our concern here) scientific experts, since it is likely that experts on both sides will present a long repertoire of formal (and informal) credentials.

One possible solution for the non-expert is to resort to a 'meta-expert'. ${ }^{170}$ That is, another expert that the non-expert has reason to believe is capable of properly evaluating the conflicting experts' credentials. But here we face the following question: how can the non-expert justifiably identify the proper 'meta-experts'? Will the non-expert also rely on credentials to do such a thing? We can now start seeing how this route just pushes the inquiry a level up, thus leading us towards an unworkable regression.

165 Ibid p. 1622.

166 Ibid p. 1624.

${ }^{167}$ Brewer includes reputation as a species of credentials (see Ibid p. 1624).

168 Ibid p. 1625.

${ }^{169}$ It is important to point to the fact that Brewer is assuming here that the kind of knowledge necessary to adjudicate between experts' credentials falls within the same domain of expertise of the knowledge necessary answer the relevant question under consideration. However, if we consider them as to distinctive domains of expertise, we might open up a new set of possible evidential resources with which the non-expert can assess the situation (Almassi, supra $n$ 29, p. 137).

${ }^{170}$ We should note, however, that the resort to a meta-expert might still fail to solve the problem of underdetermination, as developed below, since a meta-expert might still conclude that the conflicting expert's credentials are matched. 
Secondly, the question-begging problem. ${ }^{171}$ This concern is related to the observation that nonexperts do not have the epistemic capacity to judge the experts' credentials while giving independent (good) reasons for it (thereby begging the question). This should be a cause of unease if we place a value on non-arbitrariness in decision-making, in particular, within a legal system.

Finally, the underdetermination problem. ${ }^{172}$ Consider the case when two experts conflict, and each holds a $\mathrm{PhD}$ from a leading institution. What should the non-expert do? Is he justified in attributing more reliability to a degree from Harvard than from Oxford? When the expert's credentials are, according to the non-expert's eyes, 'matched', it is difficult to see how resorting to credentials could prove to be a route that leads us to a viable solution to the novice/2-expert problem. It is not.

3.4.5 The two-hats solution. I now turn to discuss the solution Brewer quickly sketches in the last couple of pages of his article: the 'two-hat' solution. According to Brewer, '[o]n this model, the system seeks to ensure that one and the some decision maker has both legal legitimacy and epistemic competence with the basic formal tools of scientific analysis' ${ }^{173}$ Good analogies include that of the psychologist that has the power of voting to solve a controversy related to the association of which he is a member, and that of an economically trained judge deciding antitrust cases.

Some authors have argued that such a solution might backfire since the elimination of asymmetries of expertise between the decision-maker and the expert would not solve the problem. ${ }^{174}$ Instead, it would increase the level of complexity of legal decisions in terms of the numbers and diversity of theories and methods likely to be considered in one particular case. Hence, it would intensify the consciousness of uncertainties and risks involved in the option for one or the other element of each group of possibilities. ${ }^{175}$

However interesting such critique might seem, I believe it relies on a mistaken idea that if we close the entry to complexity, conflict will necessarily decrease and even cease. This is a mistake. It is not safe to assume that reducing uncertainty 'automatically' reduces conflict. ${ }^{176}$

\subsection{Getting out of the sceptical scenario}

After arguing against the plausibility of the proposed routes, Brewer ends his analysis with flat-out scepticism. Accordingly, he defends that in cases where we face 'competing, sincere, and roughly equally well-credentialed experts, a non-exert will on average do no better in selecting which expert to believe than one would by tossing a coin. ${ }^{177}$ Brewer believes that whenever a non-expert is called to make a decision between conflicting scientific testimonies under these conditions (roughly equal sincerity and credentials), his decision will inevitably be arbitrary from an 'epistemological' point of view, and then (from reasons to be explained below) will be arbitrary from a 'legal' point of view.

${ }^{171}$ Brewer, supra n 1, p. 1627.

${ }^{172}$ lbid p. 1630.

173 Ibid p. 1677.

${ }^{174}$ See Schuartz, supra $n 4$.

${ }^{175}$ lbid.

${ }^{176}$ SHEILA JASANOFF, THE FIFTH BRANCH: SCIENTIFIC ADVISORS AS POLICYMAKERS, 1990, pp. 07-08, analyzing expert panels within administrative agencies in the USA

${ }^{17}$ Brewer, supra n 1, pp. 1670-1671. 
This, however, keeps us at a relatively unhelpful level of abstraction. At this stage, a question naturally arises: in what percentage of cases will Brewer's worry be present? A fully sceptical view on this issue would hold that such decisions are 'always' arbitrary. Brewer himself believes this position is too strong. He then moves to embrace a 'moderately strong skeptical view', which defends that such decisions will be arbitrary in a very high number of cases, although possibly not in all of them. ${ }^{178}$ According to this view, non-expert judgements about scientific experts' conflicting propositions will be arbitrary at least in those situations where the following condition (Brewer calls it the 'underdetermination condition') is satisfied: whenever the criterion of credentials 'underdetermines' which scientific proposition should be assigned higher reliability.

Brewer then argues:

'although it would be difficult to estimate accurately the exact percentage of cases in which the underdetermination condition is in fact satisfied in the litigation setting, or in other settings, it is clearly a very significant percentage'. ${ }^{179}$

Brewer's position relies on the observation that relevant kinds of disagreement between competing experts can occur at the level of theory, the level of method, or the level of application. He seems to believe that given the multiple alternatives present to raise disagreement between experts, we should expect that the likelihood of such a thing actually happening would be high.

The likelihood of such disagreement is, of course, an empirical question. However, Brewer, by ingeniously constructing the argument as he did, was able to call the presumption on his side. The idea is the following: if there are multiple possible alternatives for disagreement, we can 'presume' that the likelihood of such disagreement actually coming to existence is high. By claiming this presumption, Brewer is able to shift the burden of proof to the other side. If he has the presumption, whoever is to argue against him should offer compelling evidence.

But then one may wonder: does Brewer deserve the presumption he claims? We can tackle this question by re-interpreting part of Brewer's enthymematic argument and structure it in the form of a modus ponens. ${ }^{180} \mathrm{His}$ argument goes something like this:

'P1. If [in most cases there will be deep disagreement between scientific experts and no criterion will yield a justified reason], then [most non-expert's decisions in the face of conflicting scientific expert testimonies are likely to be arbitrary].

P2. In most cases there will be deep disagreement between scientific experts and no criterion will yield a justified reason.

Therefore,

P3. Most non-expert's decisions in the face of conflicting scientific expert testimonies are likely to be arbitrary'

However, one philosopher's modus ponens is another philosopher's modus tollens. We have no less justification for restructuring Brewer's inference this way:

${ }^{178}$ Ibid p. 1669

179 Ibid pp. 1669-1670.

${ }^{180}$ I should highlight that this reconstruction of Brewer's argument is by no means attempting to represent his 'entire' argument in the article widely cited here. I acknowledge that the premises of the argument here represented also operate as conclusions of other arguments presented and fully elaborated by Brewer. This is important in particular for the second part of PI 'no criterion will yield a justified reason', which is Brewer's conclusion after presenting and arguing for an intricate set of reasoning. 
'P1. If [in most cases there will be deep disagreement between scientific experts and no criterion will yield a justified reason], then [most non-expert's decisions in the face of conflicting scientific expert testimonies are likely to be arbitrary].

P2. It is not the case that most non-expert's decisions facing conflicting scientific expert testimonies are likely to be arbitrary.

Therefore,

P3. It is not the case that in most cases there will be deep disagreement between scientific experts and no criterion will yield a justified reason.'

By restructuring the argument to a modus tollens form, we flip the scenario, and together the presumption. ${ }^{181}$ However, I am after more than mere burden shifting. ${ }^{182}$ Although the intuitions on which Brewer relies are persuasive, I believe that in many cases we might have good reason to render decisions by non-experts in face of conflicting scientific expert testimony as 'nonarbitrary'. In other words, there is no need to toss a coin.

At this point, it is important to notice how the discussion has so far focused on the search for an epistemic panacea. One single criterion (or set of criteria) upon which the non-expert could rely in order to make rationally justified decisions in each and every case in which he faced conflicting scientific expert testimonies. This is where I believe the discussion might have gone wrong.

There is no need to hold that any of such criteria will yield rationally justified results at 'all' times. The alternative view is to recognize that the idea of testimonial reliability operates differently within different kinds of testimony - and differently within the same kind of testimony at different times. One criterion that turned out to be sufficiently justified for practical purposes in case A may not suffice in case B. In some cases, one criterion or the other might fail. But in other situations, it might not. In specific cases, it may be possible for the non-expert to properly evaluate and compare the conflicting expert's dialectical performance. In others cases, credentials may do the trick. In others, non-experts might justifiably rely on support from fellow experts and meta-experts, track records, or interests etc. In short, it is a mistake to think that there is one basic criterion that will yield justified decisions. And it is also a mistake to think that there is some definitive set of two or three such criteria.

This idea goes back to the topic of the epistemic justification of testimony and of epistemic deference. In the discussion above, we left with one thing in mind: that it is not reasonable to assume that all testimonial KJB share the same characteristics. Here, the same insight is helpful. Given the epistemic heterogeneity of testimonies, we can argue that, in different situations, we might require from nonexperts different justificatory explanations. ${ }^{183}$ We may demand a more or less elaborate justification. We may understand the use of this or that criterion as well suited, or not.

Here, one might still argue that the proper distinction to be drawn between testimonies is between scientific and non-scientific testimonies. So that those considered 'scientific' would undermine the

\footnotetext{
${ }^{181}$ It is important to highlight that I am 'not' saying that judges or juries find themselves to a large extent in an epistemic state where they are sufficiently competent to satisfy the justificatory demands imposed on them by the legal system. My claim is different. Here, I am just arguing that it is not so easy to conclude that it is the case that in most cases there will be deep disagreement between scientific experts and no criterion will yield a justified decision.

${ }^{182}$ At the same time, I am 'not' arguing that the probability of facing conflicting scientific expert testimonies is small. In fact, I believe that the probability that in any trial we will find conflicting scientific expert testimonies is actually high. This becomes easy to see if we recognize that the formal and adversarial style of American adjudicatory and regulatory settings highlights uncertainty, and polarizes scientific opinion.

${ }^{183}$ This insight is also explicit in the idea defended earlier in this article that epistemic competence (i.e. expertise) is a matter of degree, not an all-or-nothing feature.
} 
non-expert's epistemic capacity to such an extent that would make unjustified any use by him of any criterion to try to solve conflicting scientific expert testimonies.

We should remember our discussion on expertise. There is simply no rigid watermark boundary between what counts as expert knowledge, and what does not. This boundary is fluid, constantly drawn and redrawn based on different criteria, which in turn are contingent, historically situated, and grounded in practice. Even within those testimonies considered 'scientific', or belonging to a given relevant domain of expertise, it is not the case that all of them require the same justificatory explanation, or the use of the same criteria. ${ }^{184}$

At this stage, we need to underline that all of this does not lead us to the radical idea that 'anything' can count as a good criterion at any time. In attending to a particular criterion, the non-expert is still epistemically obliged to assess its epistemic warranty. Thus, for instance, the non-expert decisionmaker still has to provide good reasons why a particular expert's track record or dialectical performance closely represents one expert's ability in a given domain of expertise. And we should be vigilant about the reasons given.

Following Goldman, we saw how the past track record indicator requires data and institutional instruments to render it workable, which should lower our expectations concerning its results. However, we still saw the potential that it might carry for cases in which 'esoteric' propositions have turned 'exoteric'. ${ }^{185}$ Following Brewer, we saw that appeal to meta-expert appraisal of conflicting experts' credibility may not always give closure for non-experts, since meta-expertise disagreement remains possible as well. But we can conceive a range of plausible circumstances ('easy cases') where differences in credentials are so wide as to render their use possible without resulting in regress, question begging, or underdetermination. We can also think about cases in which an ex ante agreement among the parties and decision-makers concerning the meta-expert would turn this into a promising route.

In any case, the conditions of persuasion with respect to the non-expert's decision when facing conflicting expert testimonies should be established in such a way that its verification is intersubjectively controllable in specific cases.

Such demand, however, should by no means be taken as an unrestricted search for situations without any risk of error. On the contrary, it should promote awareness of the inevitable risk of error. In any decision, the probability that the decision-maker wrongly takes as true (false) what is false (true) is always positive. The accountability based on intersubjectively considered good reasons should help to direct the decision maker's attention to his fallibility. ${ }^{186}$

It is further erroneous to conclude from this fact alone that legal decision-making under these circumstances requires empirical judgements, that those applying at any given criterion can give free reign to their own subjective moral convictions. ${ }^{187}$ This conclusion would only hold if we

\footnotetext{
184 As Kuhn, Lakatos and Laudan have emphasized, different 'paradigms' (or 'research traditions' or 'research programs') bring with them different sets of metaphysical and methodological elements depending on which scientific theories and claims ought to be evaluated, including accepted arguments, terminology, instruments and standards of evidence and evaluation methods etc. See, e.g. THOMAS KUHN, THE STRUCTURE OF SCIENTIFIC REVOLUTION, 1962; Thomas Kuhn, Objectivity, Value-Judgment, and Theory Choice, in THOMAS KUHN, THE ESSENTIAL TENSION, 1977, pp. 320-339; IMRE LAKATOS, THE METHODOLOGY OF SCIENTIFIC RESEARCH PROGRAMMES: PHILOSOPHICAL PAPERS VOLUME 1, 1978; and LARRY LAUDAN, PROBLEM AND ITS PROBLEMS: TOWARDS A THEORY OF SCIENTIFIC GROWTH, 1977 (with special attention to chapter 03).

${ }^{185}$ See supra note 117 and accompanying text.

${ }^{186}$ Schuartz, supra $n 4$.

${ }^{187}$ ROBERT ALEXY, A THEORY OF LEGAL ARGUMENTATION: THE THEORY OF RATIONAL DISCOURSE AS THEORY OF LEGAL JUSTIFICATION, 2010.
} 
could not conceive of any possibility of operable evaluation of legal arguments and reasoning. In such a scenario, we would then be obliged to conclude that the non-intersubjectively-testable empirical judgements of the decision makers are the decisive factor for decisions, a conclusion that few would be willing to accept.

Undoubtedly, the kinds of decision-making criteria we are dealing with cannot reduce the set of what is discursively possible to any sort of final certainty or determinacy. However, that does not mean that it is pointless to put these criteria forward in the first place. Even though they might not determine a single answer, they might shed light on the discussion by excluding clearly 'wrong', or epistemological unjustified propositions. Furthermore, they can provide 'normative reference points' to guide the reasoning process, so that the advantages and disadvantages of different proposals can be later discussed. ${ }^{188}$ Thus, they can still serve a function in providing us with useful insights on how to evaluate and discuss decisions of legal decision-makers, and then, make them accountable for their reasoning processes.

\subsection{Intellectual due process}

Before concluding, it is worth discussing the underlying idea that supports most of the inquiry undertaken in this article. This is the idea that certain rule-of-law values require epistemic non-arbitrariness in legal reasoning. ${ }^{189}$ If a non-expert cannot decide between conflicting scientific expert testimonies in a way that is not epistemically non-arbitrary, then, that decision is not legally justified, hence, not legally legitimate. This norm, to which Brewer alluded as the 'intellectual due process' norm, is a direct mandate of the broader Due Process Clause.

As Brewer himself acknowledges, much work remains to be done to fully explicate the confines of this norm. To this end, I believe one thing could be clarified. Here, an analogy to the Due Process Clause is helpful. In the case of the Due Process Clause, there is not a single procedure or act, which under verified compliance, would render the duties imposed by the due process clause as completely satisfied. Likewise, in the case of the intellectual due process, there is no single procedure or epistemic criterion, which verified compliance, would render the duties imposed by the intellectual due process norm as completely satisfied.

\section{Conclusion}

After such a long journey, I can summarize my main argument as follows. I have tried to argue that, in the face of conflicting scientific expert testimonies, one possible route to get us out of the sceptical scenario is to accept that what counts as a good criterion varies according to context. Hence, we should not rush and discharge a possible solution just because it fails to provide us with what one would deem 'rational justification' in every conceivable scenario. We should get rid of such an ambitious project and aim lower. We should admit fallibility. If we have an arsenal at our disposal, with weapons that may prove useful at different times, we do not need a nuke. This is so even if, in a very small set of cases, at the end of the day we find ourselves with no weapon at all but a coin. The good news is that in a great number of cases the non-experts facing conflicting scientific expert testimonies will 'not' need to toss it.

\footnotetext{
188 As an example, see Schuartz, supra $n 4$.

${ }^{189}$ Brewer, supra n 1, p. 1672. See also ERICA BEECHER-MONAS, EVALUATING SCIENTIFIC EVIDENCE: AN INTERDISCIPLINARY FRAMEWORK FOR INTELLECTUAL DUE PROCESS, 2007.
} 


\section{Acknowledgements}

I am in debt for thoughtful comments to Scott Brewer, Rebecca Haw, Nadav Orian Peer, Márcio Grandchamp, Ali Butler and other workshop participants at the Legal Theory Forum at Harvard Law School, at the Faculty Workshop at FGV Direito Rio, at the 2011 Doctoral Scholarship at Yale Law School, at the 8th Inter-University Graduate Conference at Cornell Law School, and at the Dissertation Workshop at Harvard Law School. 